\title{
Review \\ Diversity of Dopaminergic Neural Circuits in Response to Drug Exposure
}

\author{
Barbara Juarez ${ }^{1,2,3}$ and Ming-Hu Han ${ }^{*, 1,2,3,4}$ \\ 'Department of Pharmacology and Systems Therapeutics, Icahn School of Medicine at Mount Sinai, New York, NY, USA; ${ }^{2}$ Department of \\ Neuroscience, Icahn School of Medicine at Mount Sinai, New York, NY, USA; ${ }^{3}$ Friedman Brain Institute, Icahn School of Medicine at Mount Sinai, \\ New York, NY, USA; ${ }^{4}$ Institute for Systems Biomedicine; Icahn School of Medicine at Mount Sinai, New York, NY, USA
}

\begin{abstract}
Addictive substances are known to increase dopaminergic signaling in the mesocorticolimbic system. The origin of this dopamine (DA) signaling originates in the ventral tegmental area (VTA), which sends afferents to various targets, including the nucleus accumbens, the medial prefrontal cortex, and the basolateral amygdala. VTA DA neurons mediate stimuli saliency and goal-directed behaviors. These neurons undergo robust drug-induced intrinsic and extrinsic synaptic mechanisms following acute and chronic drug exposure, which are part of brain-wide adaptations that ultimately lead to the transition into a drug-dependent state. Interestingly, recent investigations of the differential subpopulations of VTA DA neurons have revealed projection-specific functional roles in mediating reward, aversion, and stress. It is now critical to view drug-induced neuroadaptations from a circuit-level perspective to gain insight into how differential dopaminergic adaptations and signaling to targets of the mesocorticolimbic system mediates drug reward. This review hopes to describe the projectionspecific intrinsic characteristics of these subpopulations, the differential afferent inputs onto these VTA DA neuron subpopulations, and consolidate findings of drug-induced plasticity of VTA DA neurons and highlight the importance of future projection-based studies of this system.

Neuropsychopharmacology (20 I6) 4I, 2424-2446; doi: I 0. I038/npp.20I6.32; published online 6 April 2016
\end{abstract}

\section{INTRODUCTION}

Dopamine (DA) in the mesocorticolimbic system is thought to tune attributes of rewarding stimuli by encoding the value of a reward, creating incentive salience for reward, enhancing associative learning of the reward context, and determining the predictability of a reward (Gonzales et al, 2004; Koob, 2006; Robinson and Berridge, 2000; Schultz, 2002). DA in this system has also been shown to be involved in emotion-related behaviors, particularly in the processing of stressful events (Brischoux et al, 2009; Chaudhury et al, 2012; Tye et al, 2013). Ventral tegmental area (VTA) DA neurons of the mesocorticolimbic system release DA onto neural substrates classically known to encode stimuli valence (nucleus accumbens, NAc), regulate executive control (medial prefrontal cortex, $\mathrm{mPFC}$ ), and form associative related memories (basolateral amygdala, BLA) (Russo and Nestler, 2013). These dopaminergic projections of the VTA are known to be a part of the reward and emotion-related behaviors, which are part of a key neural circuit of addiction (Hyman, 2007; Nestler, 2001). DA neurons of the VTA have

*Correspondence: Dr M-H Han, Department of Pharmacology and Systems Therapeutics, Icahn School of Medicine at Mount Sinai, Icahn Medical Institute, 1425 Madison Avenue Box 12-15, New York, NY 10029, USA, Tel: + | 212659 1729, Fax: + | 212 83| 01 |4,

E-mail: ming-hu.han@mssm.edu

Received 22 November 2015; revised 5 February 2016; accepted 22

February 2016; accepted article preview online 3 March 2016 also been shown to project to other brain regions, including the hippocampus (HPC), with a particularly heavy distribution in the ventral subiculum (vSub) and CA1 (Gasbarri et al, 1994; Scatton et al, 1980). This projection has been proposed to be important for long-term potentiation (LTP) and the representation of stimuli and environments (Lisman and Grace, 2005).

VTA DA neurons exhibit two firing patterns in vivo-a slow, asynchronous single-spike activity (tonic, $2-4 \mathrm{~Hz}$ ) and a rapid, multi-spike bursting activity (phasic, $15-30 \mathrm{~Hz}$ ) (Figure 1) (Cao et al, 2010; Grace and Bunney, 1984a, b; Tsai et al, 2009). It is thought that transitions between these two modes encode the context of rewarding stimuli, and ultimately the changes in concentration of DA at the terminal help encode salience to stimuli, promote seeking of reward, and tune reward prediction error for cueassociated behaviors (Phillips et al, 2003; Schultz, 2007). VTA DA neurons are immunohistochemically identified by the presence of tyrosine hydroxylase $(\mathrm{TH})$, a rate-limiting enzyme in the production of DA (Berger et al, 1982; JavoyAgid et al, 1981a; Javoy-Agid et al, 1981b; Margolis et al, 2006b). The VTA is also comprised of local inhibitory $\gamma$-aminobutyric acid (GABA) interneurons, projecting GABA neurons and projecting glutamate neurons (Carr and Sesack, 2000a; Lammel et al, 2014; Walsh and Han, 2014). In addition, it has been revealed that a subpopulation of midbrain DA neurons projecting to the striatum co-release glutamate and GABA onto their target neural substrates 
a

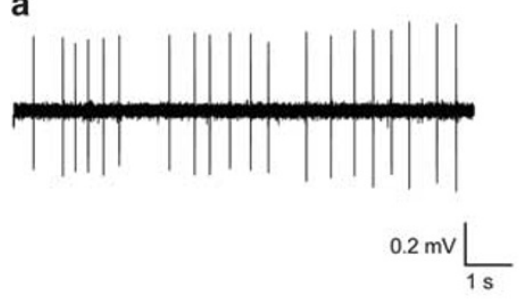

b

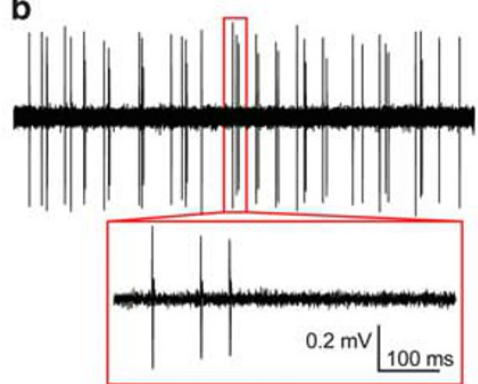

C

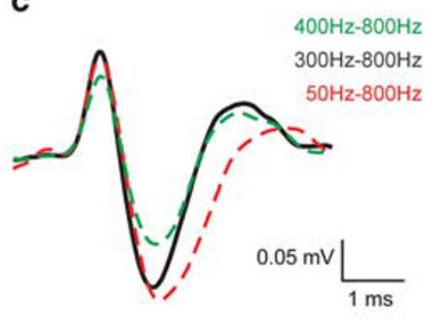

Figure I In vivo firing characteristics of VTA DA neurons. Active VTA DA neurons transition between two states of firing modes in vivo: (a) low-frequency tonic, single-spike firing and (b) high-frequency burst firing (inset shows expanded view of burst with onset occurring when two spikes fire within $<80$ ms and termination ending after > $160 \mathrm{~ms}$ of silence). VTA DA neurons have a waveform shape under filter conditions. (c) Demonstration of a single recorded VTA DA neuron under three different filters used in electrophysiology. DA, dopamine; VTA, ventral tegmental area.

(Kim et al, 2015; Stuber et al, 2010; Tritsch et al, 2012; Tritsch et al, 2014). Consequently, understanding the everemerging complexity of the VTA and the functions of its projections is a field of great interest.

The VTA is also critical for drug reward, seeking, and reinstatement (Koob and Volkow, 2010). Drugs of abuse increase DA concentrations in projection targets of the VTA and within the VTA itself (Di Chiara and Imperato, 1988; Nestler, 2005; Wise and Rompre, 1989). However, the mechanisms of how drugs of abuse cause increased DA release and increased concentrations of DA in target neural substrates are varied. Drugs of abuse can act directly on VTA DA neurons through receptor binding or ion-channel modulation to increase cell firing, through indirect mechanisms of disinhibition, or through modulation of DA transporters (DAT), which is the main clearance mechanism of DA at the synapse (Hyman et al, 2006). Ethanol can act directly on receptors and ion channels located on VTA DA neurons to increase cellular firing while simultaneously modulating GABAergic inputs onto VTA DA neurons (Brodie et al, 1990; Gessa et al, 1985; Tan et al, 2010; Theile et al, 2010). Nicotine also directly modulates the activity of VTA DA neurons through binding to a multitude of nicotinic acetylcholine receptors ( $\mathrm{nAChRs}$ ) expressed on DA neurons and glutamatergic terminals in the VTA (Laviolette and van der Kooy, 2004). The overall actions of opioids in the VTA, however, act primarily through inhibitory $\mu$-opioid receptors (MORs) expressed on GABAergic interneurons of the VTA, to reduce GABA tone and disinhibit DA neuron firing (Johnson and North, 1992a). The psychostimulant cocaine increases DA concentrations by inhibiting DATs that are present on axon terminals of VTA DA neurons, as well as inducing robust synaptic plasticity mechanisms on VTA DA neurons (Luscher, 2013; Vaughan and Foster, 2013). These drugs demonstrate the multiple mechanisms and complexity by which drugs of abuse modulate DA levels in the mesocorticolimbic system.

Recently, further elucidation of the characteristics and function of the mesocorticolimbic DA circuit has described heterogeneity of VTA DA neurons based on projectionspecific, intrinsic receptor/ion-channel distributions and selective afferent inputs (Chaudhury et al, 2012; Ekstrand et al, 2014; Friedman et al, 2014; Lammel et al, 2008). These subpopulations can often be anatomically differentiated on a medial-lateral, posterior-anterior, and dorsal-ventral manner
(Ford et al, 2006; Lammel et al, 2008; Margolis et al, 2006a; Margolis et al, 2006b; Margolis et al, 2008). The projectionspecific molecular, functional, and anatomical differences must be taken into account when determining the actions of drugs of abuse on DA function. To fully understand the mechanisms of drug-induced plasticity, one must now understand how these subpopulations are uniquely modulated after drug exposure to encode reward salience and cueinduced behaviors that effect drug reinstatement (relapse). This review will describe the intrinsic characteristics of subpopulations of VTA DA neurons, define the differential synaptic control of these subpopulations, and delve into the multivaried mechanisms of drug-induced neuroadaptations that alcohol, nicotine, opiates, and cocaine induce on VTA DA neurons while highlighting studies that have identified atypical VTA DA plasticity mechanisms.

\section{FUNCTIONALLY DIVERSE INTRINSIC CHARACTERISTICS OF VTA DOPAMINE NEURONS}

\section{Conventional Methods of Identifying VTA Dopamine Neurons In Vitro}

VTA DA neurons of the mesocorticolimbic system project to the NAc, the mPFC, and the BLA. Since VTA DA neurons lose their characteristic phasic activity in ex vivo slice preparations, a number of conventional electrophysiological and functional criteria have been used to identify DA neurons in vitro (Grace and Bunney, 1984a, b; Grace and Onn, 1989; Kitai et al, 1999). Historically, researchers have used the conventional electrophysiological criteria that were associated with DA neurons of the substantia nigra pars compacta $(\mathrm{SNc})$ to identify DA neurons of the VTA. These criteria included the presence of slow pacemaker firing, a long action potential waveform, a hyperpolarizationactivated current $\left(I_{\mathrm{h}}\right)$, the presence of small conductance calcium-activated potassium (SK) channels, and autoinhibition through the high-affinity DA D2 receptors that are linked to $G$ protein-coupled inwardly rectifying potassium channels (GIRK) (Liss and Roeper, 2008; Margolis et al, 2006b; Morikawa and Morrisett, 2010).

However, DA neurons have proved difficult to conventionally classify in the VTA. $I_{\mathrm{h}}$ is mediated via hyperpolarization-activated cyclic nucleotide-gated cation channels (HCN channels) and were once thought to be a 
Table I Distinct Electrophysiological Properties of VTA-IsNAc and VTA-mPFC DA Neurons

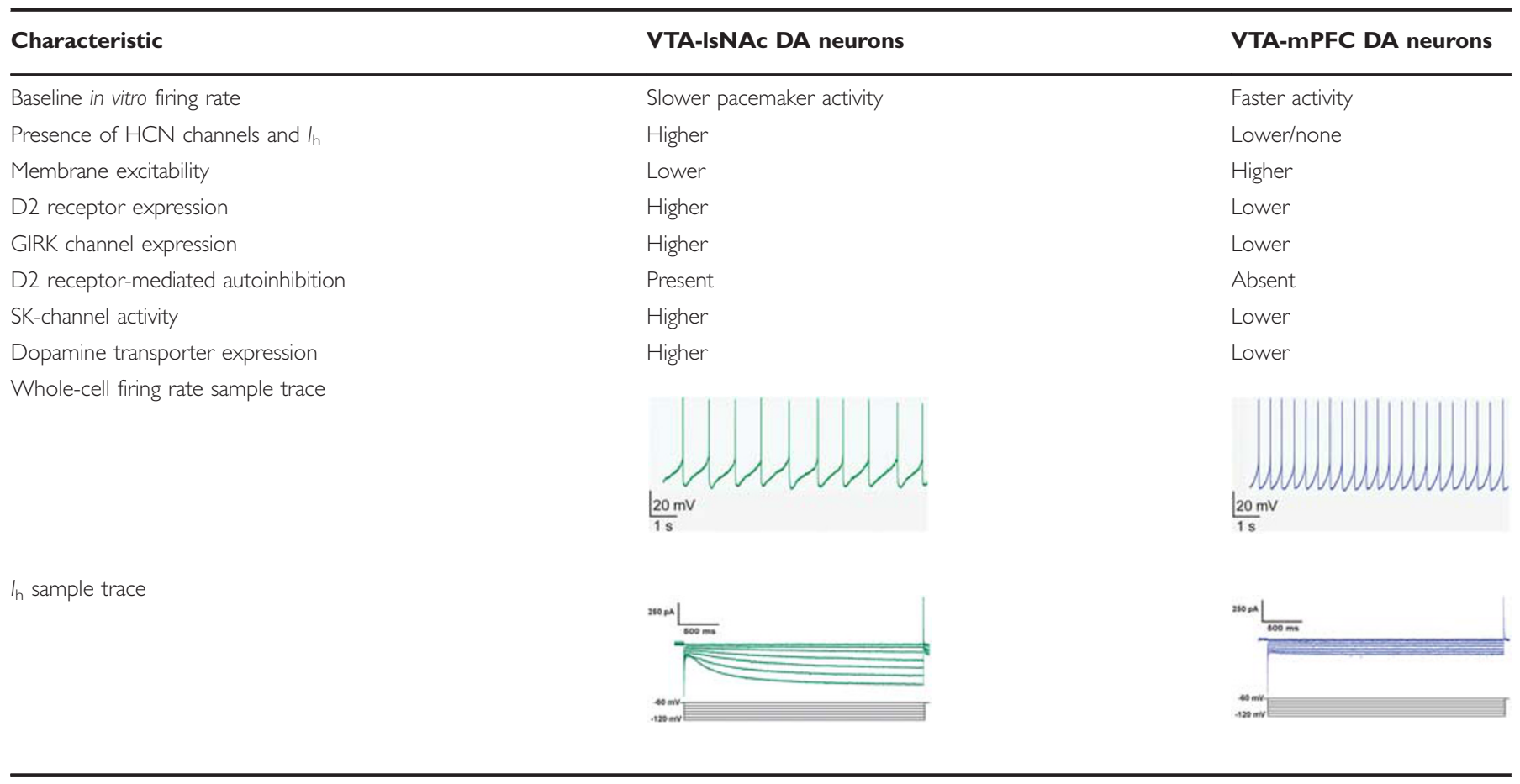

reliable criterion for functional identification of DA neurons. However, although DA neurons of the SNc consistently display $I_{\mathrm{h}}$ to maintain pacemaker activity, VTA DA neurons have shown great heterogeneity in the expression and function of $I_{\mathrm{h}}$ (Liss and Roeper, 2008; Margolis et al, 2010; Margolis et al, 2006b). These investigations have varied in the rodent models used (rat or mouse), age of model (adolescent or adult), and recording conditions (room temperature or $32^{\circ} \mathrm{C}$ ), yet they have consistently identified a posterior-medial subpopulation of putative TH-expressing DA neurons in the VTA that display little or no $I_{\mathrm{h}}$ currents in acute slice preparations (Ford et al, 2006; Friedman et al, 2014; Lammel et al, 2008; Margolis et al, 2006b). This posterior-medial subpopulation of VTA DA neurons have been consistently shown to project to the $\mathrm{mPFC}$ and also display higher baseline activity profiles (Lammel et al, 2008). Another marker of DA neurons in the SNc was the presence of apamin-sensitive SK channels (Liss and Roeper, 2008). These channels have been shown to generate the distinguishing after hyperpolarization of VTA DA neuron waveforms (Ji et al, 2009; Ji and Shepard, 2006). It is also a channel critical for the phasic activity pattern generation of DA neurons in the SNc (Ji and Shepard, 2006; Liss and Roeper, 2008). However, SK channels were also inconsistently found across the DA neurons of the VTA. Interestingly, low SKmediated currents were correlated with little to no $I_{\mathrm{h}}$ currents (Table 1) (Lammel et al, 2008). Furthermore, there have been a number of reports of discrepancies in using D2 receptormediated autoinhibition to identify VTA DA neurons. This autoinhibition mechanism is regulated by the presence of somatodendritic D2 receptors that are linked to GIRK channels on DA neurons. Activation of D2 receptors, either through localized DA release in the VTA or the D2 receptor agonist, quinpirole, leads to hyperpolarization of the cell to inhibit firing (Beckstead et al, 2004; Labouebe et al, 2007). However, subpopulations of VTA DA neurons showed no inhibition effect to activation of these receptors (Chiodo et al, 1984). The disparate presence of these classic criteria in VTA DA neurons has called into question what constitutes the classic characteristics of DA neurons in the VTA.

\section{Intrinsic Heterogeneity Based on Projection Site}

Using circuit-tracing techniques, there have been a number of recent studies that have elucidated distinct subpopulations of VTA DA neurons of the mesocorticolimbic system based on their projection site and TH immunoreactivity. VTA DA neurons with large $I_{\mathrm{h}}$ were mostly located in the lateral VTA and project to the lateral shell of the NAc (lsNAc) (Table 1, Table 2, Figure 2, and Figure 3) while VTA DA neurons that had little to no $I_{\mathrm{h}}$ were found to be primarily distributed along the posterior-medial axes of the VTA (Table 1, Figure 2, and Figure 4). VTA DA neurons with little or no $I_{\mathrm{h}}$ project to the $\mathrm{mPFC}$, the $\mathrm{BLA}$, the NAc core (cNAc), and medial shell of the NAc (msNAc) (Table 1 and Figures 2 and 4). They also displayed higher firing rates than the typical slow pacemaker activity patterns previously attributed to VTA DA neurons, had increased membrane excitability, and showed differential homeostatic plasticity mechanisms (Table 1) (Chaudhury et al, 2012; Friedman et al, 2014; Lammel et al, 2008). Uniquely, VTA DA neurons that project to the mPFC (VTA-mPFC) lacked D2 receptor-mediated autoinhibition and display lower levels of D2 and GIRK channel mRNA (Table 1) (Lammel et al, 2008). These VTAmPFC neurons also have a very low expression of DAT when compared with mesolimbic projecting neurons (Table 1) (Lewis et al, 2001; Sesack et al, 1998). Indeed, it has been shown that the mPFC maintains higher concentrations of 
Table 2 VTA Output and Input Circuits and the Related Studies

\begin{tabular}{|c|c|}
\hline Projection & Reference \\
\hline \multicolumn{2}{|l|}{ VTA output } \\
\hline $\begin{array}{l}\text { DOPAMINEGIC: VTA-lateral shell NAc, VTA-medial shell NAc, VTA-NAc } \\
\text { core, VTA-BLA, and VTA-mPFC }\end{array}$ & Lammel et al, 2008; Chaudhury et al, 20 I2; Friedman, et al, 2014 \\
\hline GABAergic: VTA-NAc & Omelchenko and Sesack, 2005 \\
\hline \multicolumn{2}{|l|}{ VTA input } \\
\hline NAc-VP and VP-VTA & Kalivas et al, 1993; Wu et al, 1996; Floresco et al 2003; Zahm and Heimer, 1990 \\
\hline LHb-RMTg-VTA & Matsumoto and Hikosaka, 2007; Lammel et al, 2012 \\
\hline LHb-VTA-PFC & Lammel et al, 2012 \\
\hline BNST-VTA & $\begin{array}{l}\text { Georges and Aston-Jones, 200 I; Georges and Aston-Jones, 2002; Geisler and } \\
\text { Zahm, 2005; Jennings et al, } 2013\end{array}$ \\
\hline LH-VTA & Peyron et al, 1998; Fadel and Deutch, 2002 \\
\hline RMTg-VTA & Barrot, 2014; Sanchez-Catalan et al, 2014 \\
\hline LC-VTA & Mejias-Aponte et al, 2009 \\
\hline LDT-VTA & $\begin{array}{l}\text { Forster and Blaha, 2000; Lodge and Grace, 2006; Omelchenko and Sesack, } \\
\text { 2005; Lammel et al, 2011, } 2012\end{array}$ \\
\hline PPTg-VTA & Clements and Grant, 1990; Oakman et al, 1995; Floresco et al, 2003 \\
\hline VTA GABA projecting neuron-NAc & Omelchenko and Sesack, 2005 \\
\hline CeA-VTA & Gonzales and Chesselet, 1990; Wallace et al, 1992 \\
\hline mPFC-VTA, OFC-VTA & $\begin{array}{l}\text { Gariano and Groves, 1988; Sesack and Bunney, 1989; Carr and Sesack, 2000b; } \\
\text { Takahashi et al, 20l I }\end{array}$ \\
\hline
\end{tabular}

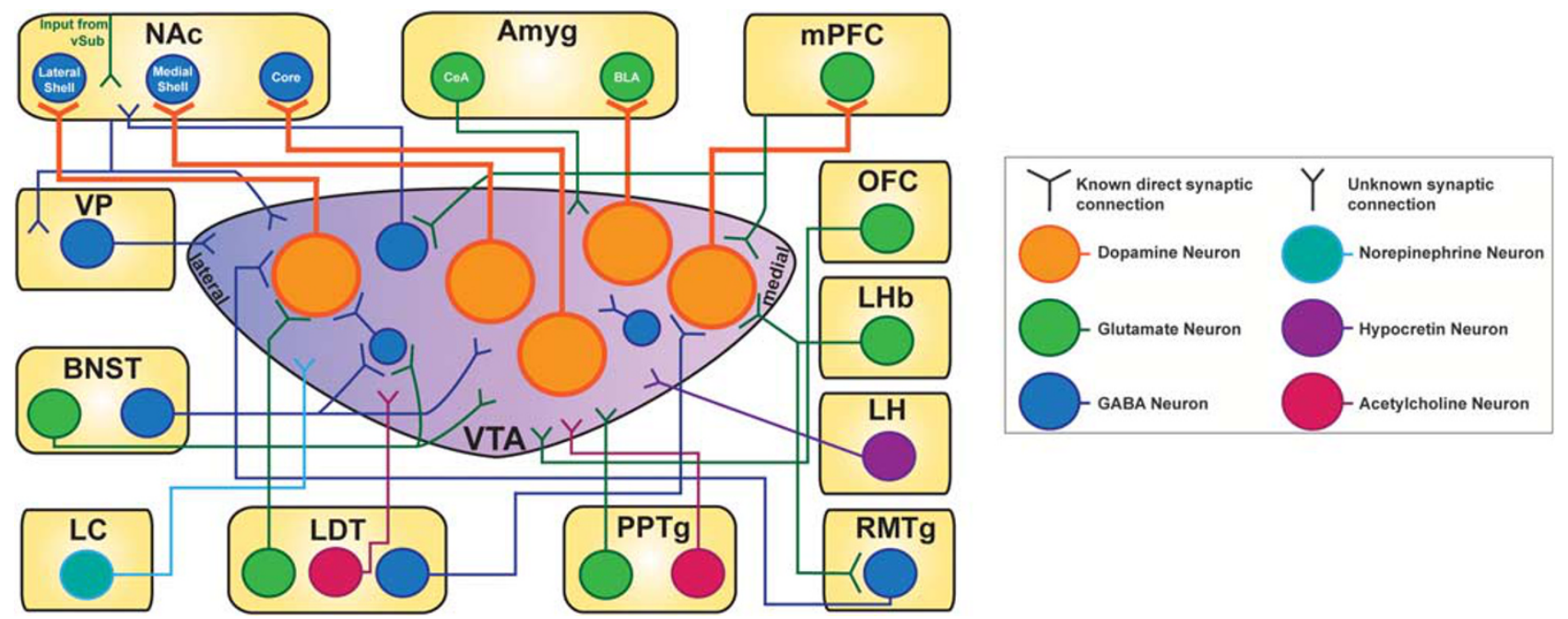

Figure 2 Schematic representation of VTA input and output. Amyg, amygdala; BNST, bed nucleus of stria terminalis; LH, lateral hypothalamus; LC, locus coeruleus; LDT, laterodorsal tegmental nucleus; LHb, lateral habenula; mPFC, medial prefrontal cortex; NAc, nucleus accumbens; OFC, orbitofrontal cortex; PPTg, pedunculopontine tegmental nucleus (aka PPN); RMTg, rostral medial tegmental nucleus; VP, ventral pallidum; vSub, ventral subiculum; VTA, ventral tegmental area.

DA for longer amounts of time compared with the striatum (Garris et al, 1993; Moghaddam et al, 1993). This decreased uptake for DA in VTA-mPFC DA neurons could be of functional importance for the DA in working memory and executive behaviors in the cortex.

In conjunction with reduced uptake and D2 autoreceptors on VTA dopaminergic terminals in the mPFC is a differential DA metabolic turnover mechanism compared with subcortical regions (Bannon and Roth, 1983). The enzyme catechol-o-methyltransferase (COMT) has a role in the metabolism of DA in the PFC (Bilder et al, 2004; Guldberg and Marsden, 1975). COMT downregulation leads to increased DA in the PFC, but not the NAc (Gogos et al, 1998; Huotari et al, 2002). COMT-knockout (KO) mice have increased DA levels in the PFC in vivo, but not in subcortical regions, when blocking norepinephrine transporters (NET) and monoamine oxidation (MAO), suggesting a critical role of COMT and its regulation with NET and 


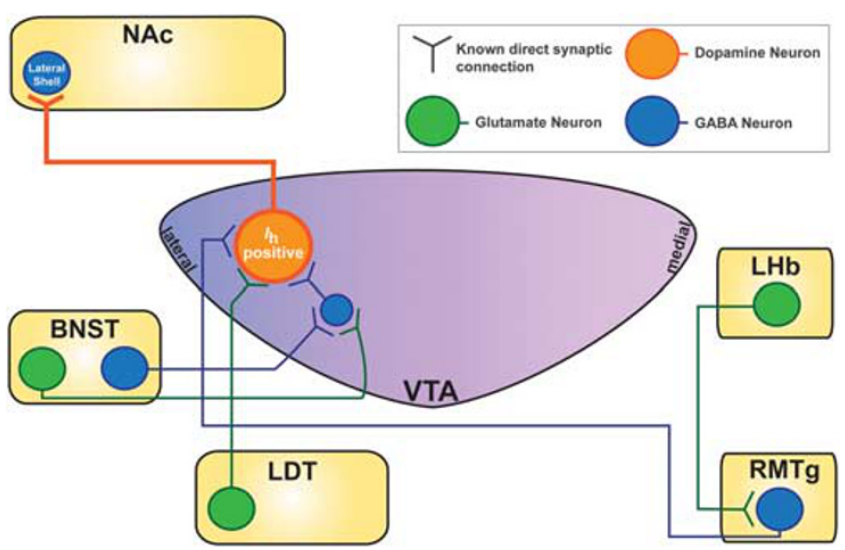

Figure 3 Known inputs onto $l_{h}$-positive VTA DA neurons. VTA DA neurons that project to specific regions of the mesocorticolimbic system can often be identified by the presence and absence of an $I_{h}$ current. This figure shows $I_{h}$-positive circuits. BNST, bed nucleus of stria terminalis; DA, dopamine; I h, hyperpolarization-activated cation channel current; LDT, laterodorsal tegmental nucleus; LHb, lateral habenula; NAc, nucleus accumbens; RMTg, rostral medial tegmental nucleus; VTA, ventral tegmental area.

$\mathrm{MAO}$ in differential DA clearance rates in the PFC (Kaenmaki et al, 2010).

If VTA DA neurons in early drug-induced plasticity studies were once classified based on the conventional criteria of the presence of a large $I_{\mathrm{h}}$ or D2 receptor-mediated autoinhibition, those studies might have preferentially identified plasticity mechanisms of VTA DA neurons that projected exclusively to the specific subcortical regions. This should be taken into account when interpreting earlier work of studying druginduced plasticity that based their identification of DA neurons in vitro on these criteria. Indeed, functional encoding of depressive behaviors were found to be different amongst subpopulations of VTA DA neurons (Chaudhury et al, 2012) and a homeostatic plasticity mechanism of balancing potentiated $I_{\mathrm{h}}$ and inhibitory potassium $\left(\mathrm{K}^{+}\right)$currents, associated with resilience to stress, were found to be exclusively occurring in VTA-NAc DA neurons (Friedman et al, 2014). Following this discovery of projection-specific stress-related adaptations, it is possible that drugs of abuse, which act via ion-channel modulation, receptor binding, or DAT inhibition, may also induce heterogeneous adaptations across projection-specific subpopulations. Thus, understanding possible differential mechanisms of drug-induced plasticity across distinct VTA DA populations could support the multivaried roles of DA found in the mesocorticolimbic system. Below, we will discuss our current understanding of drug-induced plasticity mechanisms and try to dissociate the findings based on each subpopulation.

\section{A CIRCUIT-LEVEL VIEW OF NEURAL FUNCTION AND BEHAVIORAL CONTROL OF VTA DOPAMINE NEURONS}

\section{In vivo Characteristics of VTA Dopamine Neurons}

VTA DA neurons can be reliably identified in vivo by their slow waveform of $>2.5 \mathrm{~ms}$ (Figure 1a and c) and large startnegative trough segment of $\geqslant 1.1 \mathrm{~ms}$ (Figure 1c) (Grace and Bunney, 1983a, b; Henry et al, 1989; Ungless and Grace,

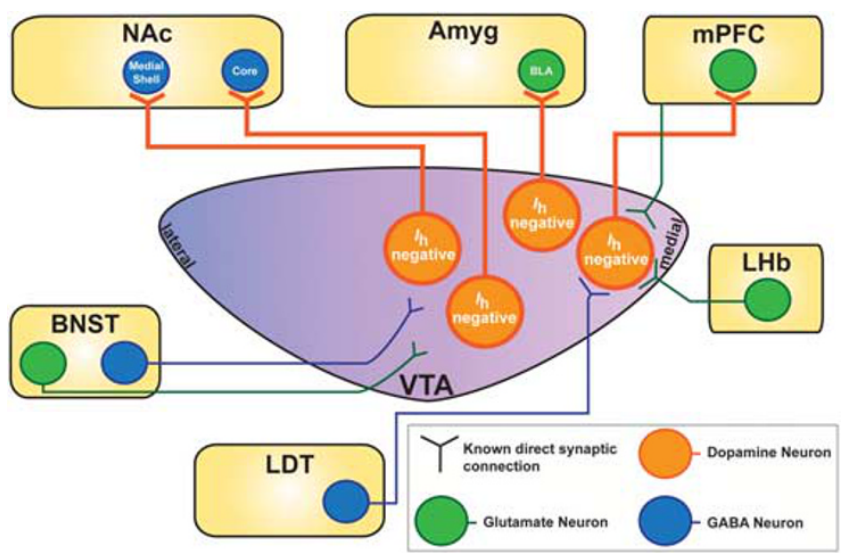

Figure 4 Known inputs onto $I_{h}$-negative VTA DA neurons. This figure shows known direct synaptic inputs onto $I_{h}$-negative neurons and their projection targets. Amyg, amygdala; BNST, bed nucleus of stria terminalis; DA, dopamine; $I_{h}$, hyperpolarization-activated cation channel current; LDT, laterodorsal tegmental nucleus; LHb, lateral habenula; mPFC, medial prefrontal cortex; NAc, nucleus accumbens; RMTg, rostral medial tegmental nucleus; VTA, ventral tegmental area.

2012; Ungless et al, 2004). VTA DA neurons are known to express and transition between two firing states in vivo, a single-spike tonic firing $(1-10 \mathrm{~Hz})$ and a transient, multispike phasic firing (15-30 Hz) (Figure 1b) (Cao et al, 2010; Grace and Bunney, 1984a, b; Grace and Onn, 1989; Walsh and Han, 2014). These two active states contribute to the tonic-phasic DA hypothesis where tonic VTA DA activity sets a low background DA level in downstream regions, whereupon the concentration of DA is significantly elevated with behaviorally significant stimuli (Bilder et al, 2004; Floresco et al, 2003).

Modifying filter parameters during recording can alter the waveform of putative VTA DA neurons (Figure 1c). Although sampling a large number of neurons can eliminate the possibility of misidentification of VTA DA neurons in vivo, the risk of misidentification in smaller neuronal samples could be ameliorated with stringent filtration settings during recording, followed by immunohistochemical verification for the presence of $\mathrm{TH}$ after recording (Ungless and Grace, 2012; Ungless et al, 2004). In addition, monitoring D2 receptor-mediated autoinhibition is also a way to identify VTA DA neurons in vivo, but excludes a subpopulation of VTA DA neurons that do not have strong autoinhibition (Chiodo et al, 1984; Lammel et al, 2008).

\section{Glutamate and GABA as Regulators of Dopaminergic Firing}

Regulation of tonic and phasic firing in vivo is known to be mediated by the coordination of a number of glutamatergic, GABAergic and cholinergic afferent inputs onto VTA DA neurons (Figure 2). Activation of ionotropic glutamate receptors, including $N$-methyl-D-aspartate receptor (NMDA) receptors and $\alpha$-amino-3-hydroxy-5-methyl-4-isoxazolepropionic acid (AMPA) receptors on VTA DA neurons increases VTA DA neuron in vivo firing rate and bursting activity (Chergui et al, 1993; Georges and Aston-Jones, 2002; Johnson et al, 1992b; Zweifel et al, 2009). The VTA receives 
glutamate control from various cortical substrates. For example, VTA dopaminergic and non-dopaminergic neurons receive input from the orbitofrontal cortex (OFC) (Figure 2), a key region for the encoding of reward value and prediction error (Roesch et al, 2007; Takahashi et al, 2011). Lesioning the OFC does not affect VTA DA firing, but does cause reduced firing in non-dopaminergic VTA neurons (Takahashi et al, 2011). OFC-lesioned rats showed reduced phasic responses to unexpected reward, no suppression of firing to reward-omitted events, and weaker responses to cues that predicted the value of the reward (Takahashi et al, 2011). However, stimulating the OFC caused inhibition in $73 \%$ of recorded VTA DA neurons, no change in $13 \%$ of recorded VTA DA neurons, and excitation in $13 \%$ of recorded VTA DA neurons, demonstrating heterogeneity in OFC synaptic modulation and supporting the idea of a multisynaptic circuit of control (Takahashi et al, 2011).

The PFC has also been shown to send glutamatergic afferents to the VTA to control burst firing (Figure 2) (Gariano and Groves, 1988; Sesack and Bunney, 1989; Tong et al, 1996b). Later studies have demonstrated the importance of PFC glutamatergic input for the modulation of burst activity in VTA DA neurons. Electrical stimulation of the PFC was shown to induce bursting in the VTA, which is inhibited with ionophoretic application of the NMDA antagonist CPP, but not the AMPA antagonist CNQX, onto VTA DA neurons (Tong et al, 1996a). Interestingly, Gariano and Groves, 1988 reported an initial brief inhibition followed by activation of VTA burst activity with PFC stimulation. Tong et al hypothesized that Gariano and Groves observed an additional cellular mechanism of PFC-induced bursting after the discovery of heterogeneous burst responses in the VTA following PFC electrical stimulation. Using physiologically relevant electrical stimulation parameters, they identified one class of neurons that would burst due to an initial excitation (named 'E', 27.9\% of VTA DA neurons recorded) and another class of neurons that would burst due to excitation following a short inhibition (named rebound 'IE', 33.3\% of VTA DA neurons recorded). The mechanism of bursting in the IE subpopulation was hypothesized to be due to rebound activation of a low threshold calcium current on these neurons, similar to those neurons in the thalamus (Tong et al, 1996b). The mechanism of bursting on the $\mathrm{E}$ population was found to be directly produced by glutamate. Importantly, they noted that VTA DA neurons had the ability to switch their characteristics from $\mathrm{E}$ to IE or from IE to $\mathrm{E}$, depending on the current used, highlighting the role of and significance of PFC-VTA regulation (Sesack and Carr, 2002; Tong et al, 1996b). These differential responses to PFC stimulation and OFC ablation further highlight the heterogeneity of VTA DA neuron subpopulation connectivity.

In addition to glutamatergic inputs from cortical regions, the VTA also receives a number of excitatory inputs from subcortical brain structures that may be relevant to the integration of environmental stimuli. The extended amygdala, including the bed nucleus of stria terminalis (BNST) and the central amygdala (CeA), both send glutamatergic projections to the VTA (Figure 2) (Geisler and Zahm, 2005; Georges and Aston-Jones, 2001; Gonzales and Chesselet, 1990; Vanderschuren and Kalivas, 2000; Wallace et al, 1992). It has been demonstrated that the BNST can act as mediator between the vSub and the VTA to control firing (Jalabert et al, 2009). In addition, cholinergic and glutamatergic signaling in the VTA has been shown to be critical to regulating burst activity of DA neurons. The pedunculopontine tegmental nucleus (PPTg, also known as PPN) sends glutamatergic and cholinergic inputs to the VTA (Figure 2) (Clements and Grant, 1990; Oakman et al, 1995). Increasing activity from the PPTg was shown to selectively increase bursting activity in already active VTA DA neurons to lead to increased concentrations of DA in the NAc (Floresco et al, 2003). In mice lacking NMDA receptors in VTA DA neurons, the PPTg no longer drove burst activity (Zweifel et al, 2009). In addition, glutamatergic and cholinergic afferents from the laterodorsal tegmental nucleus (LDT) were found to be critical regulators of VTA DA phasic activity and consequent increased DA release in the NAc (Figure 2) (Faure et al, 2014; Forster and Blaha, 2000; Lodge and Grace, 2006).

In addition to inhibitory control from VTA GABAergic interneurons, VTA DA neurons also receive inhibitory afferents from a number of regions that can control VTA DA activity in vivo (Figure 2). Using retrograde tracing techniques, investigators discovered that there are strong GABAergic innervations originating from the NAc shell and the ventral pallidum (VP) (Figure 2) (Kalivas et al, 1993; Wu et al, 1996; Zahm and Heimer, 1990). Eliminating the GABAergic tone from the VP by activating the hippocampal vSub-NAc-VP loop was found to increase the number of asynchronous tonic firing DA neurons in the VTA, without affecting overall increases in firing rate or bursting activity, suggesting that GABAergic VP afferents control a number of quiescent cells (Figure 2) (Floresco et al, 2003). A region found caudal to the VTA, the rostral tegmental nucleus (RMTg), has also been observed to be a major inhibitory source for dopaminergic neurons in the SNc and the VTA (Figure 2) (Barrot, 2014; Sanchez-Catalan et al, 2014).

\section{Differential Afferent Synaptic Control Over Subpopulations of VTA DA Neurons}

Importantly, studies have demonstrated that not all VTA DA neurons receive the same afferent inputs, and often these VTA DA neurons can be dissociated from one another based on the presence of $I_{\mathrm{h}}$, their projection site or regional distributions across the VTA (Figures 3 and 4, and Table 2). The glutamatergic afferents from the PFC synapse differently on cellular populations in the VTA. DA neurons that project to the $\mathrm{mPFC}$, a typically $I_{\mathrm{h}}$-negative population, receive direct excitatory glutamatergic feedback from the PFC (Figure 4) (Carr and Sesack, 2000b). VTA GABAergic projecting neurons to the NAc also receive glutamatergic control from the PFC (Carr and Sesack, 2000b).

There are also dissociable afferent synapses from subcortical regions onto VTA DA subpopulations. Studies showed that LDT excitatory afferents synapse specifically on VTA DA neurons projecting to the NAc (VTA-NAc) (Figure 3) (Lammel et al, 2011; Omelchenko and Sesack, 2005). Conversely, VTA DA neurons projecting to the mPFC (VTA-mPFC) receive inhibitory GABAergic afferents from the LDT (Figure 3) (Omelchenko and Sesack, 2005). Additionally, norepinephrine (NE) inputs from the locus coeruleus (LC) were demonstrated to be distributed across the VTA, with denser varicosities distributed across the 
medial (central) portions of the VTA (Figure 2) (MejiasAponte et al, 2009). Recently, an extensive tracing study revealed input-output connections of VTA DA neurons (Beier et al, 2015).

Understanding how cortical and subcortical afferents onto subpopulations of VTA DA neurons are differentially altered after drug exposure from a circuit perspective could generate a new understanding of drug-motivated behaviors. The synaptic strength of glutamatergic signals onto VTA DA neurons can be observed in vitro by measuring the currents mediated by ionotropic AMPA and NMDA glutamate receptors. AMPA receptors are tetrameric proteins that can be composed of four different types of subunits. AMPA receptors are quickly activated by glutamate and help depolarize the cell with the passage of small cations. This depolarization in turn helps activate the voltage-sensitive glutamate NMDA receptors, which passes small cations and, importantly, calcium. This increase in calcium influx is important for activation of many second messenger systems and for the formation of longer lasting plasticity. The functions between these two receptors can be measured in vitro by measuring currents mediated by AMPA and NMDA receptors and creating an AMPA/NMDA ratio. Alteration of this AMPA/NMDA ratio is one measure of drug-induced synaptic plasticity, as it alludes to the effectiveness of glutamatergic plasticity mechanisms on AMPA receptors and NMDA receptors.

In addition, another measure of synaptic strength is the rate of induction of LTP, using high-frequency stimulations, or long-term depression (LTD), using low-frequency stimulation, at glutamatergic or GABAergic synapses. Since the subpopulations of VTA DA neurons receive unique glutamatergic and GABAergic afferent modulation, it is critical to first identify the source of glutamatergic or GABAergic signals on a subpopulation of VTA DA neurons using advanced circuit-tracing techniques, then observing and altering the strength of these signals after drug exposure using optogenetics to see how a circuit is altered. The differential afferent input control highlights the possibility that subpopulations of VTA DA neurons can serve specific functions in behavioral regulation, particularly because of the diverse roles these regions have in processing environmental stimuli. There is now a critical need to understand these circuits, particularly to identify specific mechanisms of druginduced plasticity.

\section{Neuromodulators and Their Actions on VTA DA Neurons}

DA neurons receive modulatory inputs from substrates that release a number of neuropeptides and steroid hormones. These modulators have slow and long-lasting actions through $G$ protein-coupled receptors, to activate second messenger systems in neurons. VTA DA neurons express a number of these receptors, which ultimately influence synaptic communication between fast-acting excitatory and inhibitory afferents. Here, we will discuss the varied roles that the neuromodulators hypocretins (hcrt, also known as orexins), corticotrophin releasing factor (CRF) and glucocorticoids have in modulating VTA DA neural activity.

In addition to sending GABAergic and glutamatergic projections to the VTA, the lateral hypothalamus $(\mathrm{LH})$ sends robust hcrt input to the VTA (Figure 2) (Fadel and Deutch, 2002; Peyron et al, 1998). The LH synthesizes hypocretin-1 (hcrt-1/orexin A) and hypocretin-2 (hcrt-2/orexin B) (Peyron et al, 1998; Sakurai et al, 1998). Hcrt-1 has a higher affinity for Gq-coupled receptor hypocretin receptor-1 (hcrtR1); hcrt-2 shows equal affinity for hcrt-R1 and hcrt-2R, which is coupled to $\mathrm{Gq}$ and Gi/o receptors (Sakurai et al, 1998; Zhu et al, 2003). The VTA is known to express both receptors (Korotkova et al, 2003; Narita et al, 2006). In vivo infusion of hcrt-1 into the VTA was shown to increase DA release in the $\mathrm{mPFC}$ and $\mathrm{mNAc}$, but not the NAc core (Narita et al, 2006; Vittoz and Berridge, 2006). It has been suggested that this activation of DA release could be mediated through hcrt-1's ability to potentiate NMDAR transmission (Borgland et al, 2006; Morikawa and Morrisett, 2010). Modulating the hcrt system in awake and behaving animals has been known to affect arousal (hcrt-2) and strengthen cued-reinstatement behaviors (Korotkova et al, 2006; Smith et al, 2009). Importantly, horts have been shown to have a critical role in mediating the associative and cueinduced reinstatement properties of multiple classes of drugs, including alcohol, nicotine, morphine, and cocaine (Harris et al, 2005; Hollander et al, 2008; Lawrence et al, 2006; Narita et al, 2006). The observed role of hcrts in mediating DA release, VTA DA synaptic activity and reward seeking makes it an important neuropeptide in the study of drug-induced plasticity.

Interestingly, there have been numerous reports of heterogeneous responses to hcrt in the VTA. Hcrt-1 infusion in vivo preferentially activated DA neurons of the caudomedial VTA, as determined by c-fos immunoreactivity (Vittoz et al, 2008). Korotkova et al, 2003 identified three classes of DA neurons after application of hcrt-1 in acute VTA brain slices: one showed tonic activation; another showed inactivation; and a third showed bursting-like activation in slice. These differential, and possibly subpopulation-specific effects, of hcrt signaling via the $\mathrm{LH}$ could be informative to the dissection of subpopulations on VTA DA neurons.

The VTA is also an important target for the stress-related neuropeptide, CRF (sometimes referred to as corticotrophin releasing hormone-CRH) (Swanson et al, 1983). The VTA receives CRF from projecting terminals of the BNST, the $\mathrm{CeA}$, the paraventricular nucleus of the hypothalamus (PVN), and even from local CRF synthesizing neurons in the VTA (Grieder et al, 2014; Korotkova et al, 2006; Rodaros et al, 2007). This diversity of CRF input into the VTA highlights the VTA's role of integrating environmental and intrinsic cues for behavioral output. CRF binds to two types of $\mathrm{G}$ protein-coupled receptors, CRF-R1 (high affinity) and CRF-R2 (low affinity), both of which are expressed in the VTA (Sauvage and Steckler, 2001; Ungless et al, 2003; Van Pett et al, 2000). In addition, CRF-binding protein (CRF-BP) was found to be critical for CRF's actions in the VTA (Ungless et al, 2003). CRF containing terminals make both asymmetric (excitatory) and symmetric (inhibitory) synapses in the VTA on both dopaminergic and non-dopaminergic cells (Tagliaferro and Morales, 2008). Interestingly, in the same anatomical investigation, the experimenters discovered that only a subpopulation of VTA DA neurons expressed CRF-BP, highlighting again the importance of elucidating the heterogeneous 
mechanisms of action of VTA DA neurons. CRF's role in stress-related, drug-induced plasticity and behaviors will be discussed further below.

The neuropeptide CRF/CRH from the hypothalamus also causes the activation of the stress-reactive hypothalamuspituitary-adrenal (HPA) pathway, which ultimately releases corticosteroids from adrenal glands. Dysregulation of this HPA activation can lead to a host of neuropsychiatric disorders (de Kloet et al, 2005). One type of corticosteroid, glucocorticoids (GCCs), has potent actions in the mesocorticolimbic system during stressful events (Piazza and Le Moal, 1996). Low concentrations of GCCs bind with high affinity to mineralocorticoid receptors (MRs) while the lower affinity glucocorticoids receptors (GRs) are activated during times of higher GCC release (McEwen et al, 2015). Adrenalectomy reduces DA release in the lsNAc and injection of corticosterone to mimic GCC replacement restored DA function (Barrot et al, 2000). Differential effects of GCC modulation on DA release are dependent on the severity of stress (acute vs chronic) (Marinelli and Piazza, 2002; Pacak, 2000). GCCs also act to regulate VTA DA neural activity to through MR regulation of glutamate release and subsequent NMDA-dependent burst firing (Overton et al, 1996). Functioning GRs were determined to be necessary for the stress-induced enhancement of AMPA/ NMDA ratio on VTA DA neurons (Saal et al, 2003). Moreover, socially defeated mice with intact GR expression in the VTA exhibit increased firing frequency and bursting, while VTA DA neurons in mice without GRs in D1 neurons fail to mount a hyperexcitable response, suggesting a GRdependent interaction between dopaminoceptive and dopaminergic populations in the mesocorticolimbic circuit following stress (Barik et al, 2013). The biphasic modulation of GCCs, the necessity of glutamatergic signaling and the control of VTA DA firing between GCC responsive neural substrates of the emotion-related circuit demonstrate the tightly regulated mechanisms by which GCCs modulate DA dynamics in the mesocorticolimbic system.

\section{The VTA Processes Both Appetitive and Aversive Events}

Increases in VTA dopaminergic signaling is known to be critical for signaling the attributes of rewarding or appetitive stimuli (Hamid et al, 2015; Schultz, 2002). Interestingly, VTA DA neurons also serve as a substrate for signaling stressful or aversive events through changes in phasic activity (Brischoux et al, 2009; Chaudhury et al, 2012; Matsumoto and Hikosaka, 2007). Classically, VTA DA neurons were thought to be inhibited during aversive stimuli (Schultz et al, 1997). However, evidence has suggested that aversive stimuli have diverse effects on the regulation of VTA DA subpopulation neuronal activity. Both chronic restraint stress in rats and chronic social defeat stress in mice have been shown to induce long-term increases in VTA DA activity and bursting in vivo (Anstrom and Woodward, 2005; Chaudhury et al, 2012; Valenti et al, 2011). Conversely, rapidly inhibiting VTA DA neuron activity was demonstrated to relieve depressive symptoms (Chaudhury et al, 2012). The increased in vivo activity observed in VTA DA neurons following social defeat was found in an in vitro preparation to be exclusive to the population of DA neurons projecting to the NAc; VTA neurons projecting to the $\mathrm{MPFC}$ displayed hypoactivity following social defeat stress (Chaudhury et al, 2012). Interestingly, footshock stress has been shown to rapidly inhibit or activate subpopulations of VTA DA neurons (Brischoux et al, 2009; Valenti et al, 2011). A population of those inhibited neurons were observed to show increased firing at the termination of the footshock, suggesting the termination of aversive stimuli was found to be rewarding (Brischoux et al, 2009). On the molecular level, NMDA receptors were found to be critical to the activation of VTA DA neurons in aversive situations (Zweifel et al, 2011). These studies highlight the discovery of VTA DA subpopulations in the response to stress and aversive stimuli.

The differential glutamatergic and GABAergic synaptic connections described above may underlie the ability of the VTA to respond to both appetitive and aversive stimuli. Interfering with ventral HPC (vHPC)/vSub circuits have demonstrated that the vHPC region is critical in modulating the population of active and inactive VTA DA neurons. Inactivating the $\mathrm{vHPC}$ prevents or reverses the observed footshock and restraint stress increases in population activity found in the subset of VTA DA neurons (Valenti et al, 2011).

With the advent of circuit dissecting techniques, a number of studies have delved into dissociating the appetitive and aversive behavioral responses mediated by GABAergic and glutamatergic afferents onto VTA DA neurons. The BNST sends divergent glutamatergic and GABAergic projections to the $I_{\mathrm{h}}$-positive or -negative VTA neurons to encode aversive properties uniquely based on their medial to lateral synaptic targets (Figures 3 and 4) (Jennings et al, 2013). In addition to the BNST, Lammel et al demonstrated that LDT glutamatergic afferents synapse onto lateral VTA (IVTA) DA neurons that project to the lsNAc (Figure 3). Optogenetically activating this LDT-lVTA-lsNAc circuit in one chamber during training sessions of conditioned place preference (CPP) caused a strong preference for the optically stimulated side (Lammel et al, 2012). In contrast, glutamatergic synapses originating from the lateral habenula $(\mathrm{LHb})$ can synapse on medial VTA (mVTA)-mPFC DA neurons or onto GABAergic RMTg neurons that then project to IVTA-lsNAc neurons or medial PFC (Figures 3 and 4); optically stimulating glutamatergic $\mathrm{LHb}$ afferents that project to mVTA neurons or RMTg-lVTA neurons caused significant conditioned place aversion (Lammel et al, 2012).

The heterogeneous responses of VTA DA neuron subpopulations to appetitive and aversive stimuli and their differential regulation by cortical and subcortical inputs highlight the critical need for the dissection of functionally distinct VTA DA neuron circuits. The molecular basis of this encoding has been recently discussed in a thorough review (Pignatelli and Bonci, 2015). Below, we will discuss the ability of the VTA to process both stressful and rewarding events to modulate drug-induced plasticity mechanisms.

\section{ACTIONS AND BEHAVIORAL EFFECTS OF DRUGS OF ABUSE}

Drug addiction is characterized as the compulsive use of a drug, even in the face of adverse consequences. This pathological behavior forms after repeated use of a drug and subsequent adaptations in many circuits of the brain. Intense investigations in both animal models and humans 
Ventral Tegmental Area

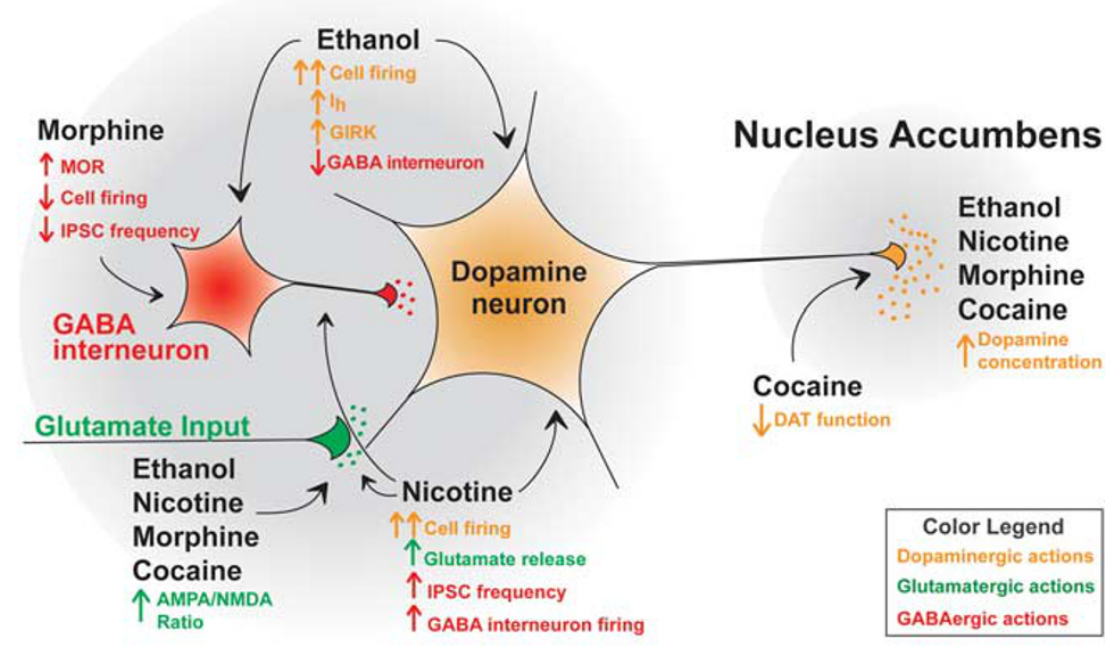

Figure 5 Drugs of abuse act in different ways to increase DA concentrations in downstream targets of the VTA. Pictured here is a VTA DA neuron projecting to the NAc. Ethanol acts directly on VTA DA neurons to increase VTA cell firing, increase $I_{h}$, and increase GIRK activity. This increase in activity leads to increased DA release. Ethanol also has effects on VTA GABA interneurons. Nicotine acts on VTA DA neurons themselves through the ligand-gated ion channel, nAChRs. Nicotine also has effects on GABA interneurons and glutamatergic afferents. Morphine acts indirectly through GABA interneurons to increase VTA DA activity. Morphine binds to MORs to decrease IPSC frequency and decrease GABAergic cell firing. This decrease in GABAergic tone disinhibits VTA DA neurons, increasing DA concentrations in the NAc. Cocaine increases concentrations of DA in the NAc by inhibiting DAT function at the VTA DA terminal. Interestingly, acute administration of ethanol, morphine, and cocaine was shown to enhance glutamatergic synaptic strength, as seen through an increase AMPA/NMDA ratio. DA, dopamine; DAT, dopamine transporter; GIRK, G protein-coupled inwardly rectifying potassium channels; I h, hyperpolarization-activated cation channel current; IPSC, inhibitory post-synaptic current; MOR, $\mu$-opioid receptor; NAc, nucleus accumbens; VTA, ventral tegmental area.

throughout the years have revealed a critical role for the dopaminergic signaling in the mesocorticolimbic system in the induction of these behaviors. VTA DA neurons undergo adaptations to acute and chronic use of drugs. Below, we will review the way alcohol, nicotine, opiates, and cocaine employ unique mechanisms to alter DA signaling and cause druginduced plasticity. In addition, we will review investigations that answer how the neuromodulators act to potentiate druginduced plasticity of VTA DA neurons.

VTA DA neurons are not a homogeneous population and can undergo distinct, projection-specific adaptations. Most of the methods used to identify VTA DA neurons in the reviewed studies used conventional criteria to identify VTA DA neurons, which the field now knows is not standard for all subpopulations. We will thus highlight studies that have found subpopulations of VTA DA neuron that underwent unique plasticity mechanisms. In addition, most of the studies in this review describe the mechanisms from passively administered drug investigations. However, there exist unique mechanisms between investigator-administered drugs of abuse and volitional consumption or selfadministration. We will highlight the investigations that observed plasticity mechanisms during self-administration, particularly during the review of how stress influences druginduced plasticity and relapse behaviors.

\section{Intrinsic and Synaptic Actions on the Activity of VTA DA Neurons in Response to Ethanol}

Alcohol addiction is marked by a person's transition from casual alcohol consumption to pathological and compulsive alcohol drinking behaviors. This transition is evidenced by a number of plasticity events that regulate reward and behavior. The VTA is a critical neural substrate for the rewarding properties of alcohol (Koob and Volkow, 2010; Nestler, 2005). Administration of ethanol (EtOH) during in vivo recordings causes an increase in the activity of VTA DA neurons (Gessa et al, 1985). In addition, EtOH administration increases DA levels in VTA target regions of the mesocorticolimbic system (Di Chiara and Imperato, 1985; Weiss et al, 1993). The mechanisms of this increased release have been widely studied and have mostly been attributed to EtOH's actions on dopaminergic cell bodies, rather than actions on dopaminergic terminals. Superfusion of EtOH in acute brain slices from rats was shown to increase firing in $89 \%$ of the VTA DA neurons recorded in a concentration-dependent manner (Brodie et al, 1990). In addition, investigators have identified that in the population of $\mathrm{EtOH}$ responsive neurons, there was variability in the sensitivity to the excitation (Brodie et al, 1990). Importantly, even after synaptic inputs were blocked, EtOH continued to increase VTA DA activity (Brodie et al, 1990; Okamoto et al, 2006). Furthermore, VTA DA neurons in isolated cell culture preparations exposed to $\mathrm{EtOH}$ still increased their neural activity (Brodie et al, 1999). These studies support the idea that EtOH can act directly through intrinsic properties on VTA DA neurons to increase cell firing (Figure 5).

Chronic EtOH exposure can produce compensatory intrinsic plasticity changes in the mesolimbic system to counter the excitatory actions of EtOH and promote EtOH seeking (Weiss and Porrino, 2002). Interestingly, two studies showed disparate responses (sensitization and tolerance) to the excitatory properties of EtOH in acute VTA slice preparations after chronic EtOH exposure. Sensitization to 
a drug refers to the drug's enhanced effects than previously described after intermittent or chronic exposure. In contrast, developing tolerance to a drug of abuse refers to the drug's inability to induce the same responses in the reward system as it once did; often, higher concentrations or continuous exposure are needed to induce the effects of tolerance. One study described that after chronic EtOH $(3.5 \mathrm{mg} / \mathrm{kg}$ twice daily i.p. injections for 21 days), VTA DA neurons had become sensitized and displayed increased firing rate and responded more robustly to superfusion of increasing concentrations of $\mathrm{EtOH}$ in vitro than in saline-treated mice (Brodie, 2002). However, Okamato et al showed that 5 days of $2 \mathrm{mg} / \mathrm{kg}$ i.p. EtOH injection decreased the EtOH-induced excitability. They attributed this tolerance effect to less effective $I_{\mathrm{h}}$ (Okamoto et al, 2006). These confounding results might be explained by the time course of the injections, $5 \mathrm{vs}$ 21 days.

It is known that in vivo activity of VTA DA neurons is significantly decreased during withdrawal (Diana et al, 1993). In this withdrawal state, there is also a significant reduction of DA release in the NAc (Weiss et al, 1996). One leading hypothesis is that this transition into a hypodopaminergic state within the mesocorticolimbic circuit drives the subject to seek more $\mathrm{EtOH}$ to stimulate DA release. Indeed, one study found that self-administration of ethanol continued until DA concentrations in the NAc were normalized (Weiss et al, 1996). It is critical to fully investigate how plasticity mechanisms over time alter VTA DA neurons, to have a better understanding of how the dopaminergic reward system alters its properties across the different stages of addiction.

EtOH's varied affects are mediated via actions on intrinsic properties through modulation of ion channels and receptors of VTA DA neurons. It has been reported that EtOH directly binds to GIRK channels to increase their function, without the need for $G$ protein-coupled receptor activation (Figure 5) (Aryal et al, 2009; Bodhinathan and Slesinger, 2014). In addition, to identify a possible mechanism for the increase in dopaminergic firing in the VTA, Morikawa and colleagues have performed extensive investigations in C57BL/6J mice into how HCN channels that regulate $I_{\mathrm{h}}$ might control this firing change. They found that EtOH increased levels of $I_{\mathrm{h}}$ and that blockade of $I_{\mathrm{h}}$ via bath application ZD7288 significantly reduced the excitatory actions of superfusion of ETOH on VTA DA neurons (Figure 5) (Okamoto et al, 2006). In addition to actions on $\mathrm{HCN}$ channels, chronic EtOH also has actions on D2-mediated autoinhibition of VTA DA neurons. One day after chronic EtOH administration $(2 \mathrm{mg} / \mathrm{kg}$ i.p. injection three times a day for 7 days), D2 receptor-mediated autoinhibition was greater and these neurons showed less desensitization (Perra et al, 2011). This, in turn, caused a greater decrease in firing after D2 activation with quinpirole (Perra et al, 2011), suggesting a functional alteration of VTA DA neurons following chronic EtOH exposure. EtOH's excitatory effects on VTA DA neurons was also shown to be modulated through regulation of SK channels (Brodie et al, 2007). Repeated administration of EtOH ( $2 \mathrm{~g} / \mathrm{kg}$ i.p injections twice daily for 5 days) significantly reduced SK channel function in VTA DA neurons 7 days after the last EtOH injection, deemed by the investigators to be post withdrawal (Hopf et al, 2007). This loss of SK channel function could lead to increases of in vivo
VTA DA bursting activity and provide increased incentive salience to EtOH (Hopf et al, 2007).

Glutamatergic and GABAergic synaptic modulation of VTA DA firing is also dramatically altered after acute and chronic EtOH exposure and withdrawal. Ethanol is known to inhibit glutamatergic NMDAR function (Lovinger et al, 1989; Morikawa and Morrisett, 2010). One injection of $20 \mathrm{mg} / \mathrm{kg}$ EtOH caused an enhanced AMPA/NMDA ratio (Figure 5) (Saal et al, 2003). This could enhance synaptic strength between VTA DA neurons and their glutamatergic input. However, there are reported strain differences in this response (Wanat et al, 2009). Alterations in GABAergic synapses are also mediators of EtOH excitability in VTA DA neurons. One in vivo acute injection of $\mathrm{EtOH}$ resulted in increased GABAergic transmission, although whether these GABAergic inputs originated from VTA GABAergic interneurons or from GABAergic inputs were not investigated (Melis et al, 2002). Bath application of $50 \mathrm{mM} \mathrm{EtOH}$ concentrations increased the frequency of GABA-mediated inhibitory post-synaptic currents (IPSCs) via an increased probability of GABA release onto VTA DA neurons from young rats (Theile et al, 2008). Furthermore, GABAergic transmission modulates the excitatory effects of EtOH on VTA DA neurons (Theile et al, 2010). However, within the VTA itself, in vivo activity of GABAergic interneurons have been shown to be inhibited with EtOH administration during recordings via an NMDAR-mediated event (Figure 5) (Stobbs et al, 2004). Overall, these differing GABAergic synaptic alterations suggest the possibility of unique populations of GABAergic afferent modulation of VTA DA firing. To date, there are few circuit investigations of the role of glutamatergic and GABAergic synapses from specific afferent inputs from brain regions that are known to regulate VTA DA firing. Given that regions such as the PFC, LDT, $\mathrm{LHb}, \mathrm{RMTg}$, and the VP are critical to in vivo firing patterns of the VTA DA system, circuit studies into how synaptic plasticity between these regions across the stages of $\mathrm{EtOH}$ treatment would provide more insight into how these neurotransmitter systems modulate VTA DA firing after ethanol exposure.

Throughout the years of alcohol research, there have been reports of heterogeneous responses to EtOH. This could be attributed to the reports of VTA DA subpopulations that have differential ion channel/receptor distributions as well as afferent inputs. Rats have shown increased responses to intracranial self-administration (ICSA) of EtOH in the posterior VTA when compared with anterior VTA ICSA of EtOH (Rodd-Henricks et al, 2000). This reinforcing behavior seems to be reliant on dopaminergic signaling in the NAc shell and the mPFC, but not the cNAc (Ding et al, 2014). Overexpression of HCN channels in the posterior VTA increased ethanol intake (Rivera-Meza et al, 2014). Acute exposure to $\mathrm{EtOH}$ in the posterior VTA increased VTA DA neuron activity, but decreased VTA DA activity from neurons in the anterior VTA and this was observed in conjunction with a decreased IPSC response in posterior VTA DA neurons and an increased IPSC response in anterior VTA DA neurons (Guan et al, 2012). Using THgreen fluorescent protein (GFP) mice, which exclusively express GFP under the TH promoter, investigators found a medial-lateral difference in the response to bath application of EtOH. mVTA DA neurons expressed increased sensitivity 
to the excitatory effects of bath application of EtOH (as little as $20 \mathrm{mM}$ ), while IVTA DA neurons were only excited at higher concentrations (100 mM) (Mrejeru et al, 2015). Resolving the diverse functions of VTA DA neuron subpopulations in mediated alcohol reward is critical.

\section{Nicotine Acts Through Diverse nAChRs on VTA DA Neurons to Regulate Neural Activity}

Nicotine, the major psychoactive component of tobacco, acts on endogenous nAChRs throughout the peripheral and central nervous system, including the mesocorticolimbic system (Marti et al, 2011; Wonnacott et al, 2005). To date, 12 different $\mathrm{nAChR}$ subunits $(\alpha 2-\alpha 10$ and $\beta 2-\beta 4)$ have been identified in the vertebrate brain (Gotti et al, 2009; Mansvelder and McGehee, 2002b). These subunits combine in heteromeric formations to create pentameric, ligand-gated ion channels that increases excitability; however, $\alpha 7-\alpha 9$ subunits can make homomeric nAChRs (Boulter et al, 1987; Couturier et al, 1990a; Couturier et al, 1990b; Deneris et al, 1989; Wada et al, 1988). These varied nAChRs differ in their affinity, conductance, and sensitivity, which overall make up their diverse physiological actions (McGehee and Role, 1995). For example, $\alpha 7$-containing nAChRs exhibit higher calcium permeability, yet $\beta 2$-containing $\mathrm{nAChRs}$ have higher affinity for nicotine (Laviolette and van der Kooy, 2004; Mansvelder and McGehee, 2002b).

Nicotinic signaling in the VTA is critical to the motivational properties of nicotine. Similar to alcohol, nicotine operates directly on VTA DA neurons to affect neural activity and cause DA release in downstream targets (Calabresi et al, 1989; Di Chiara and Imperato, 1988; Grenhoff et al, 1986; Nisell et al, 1994). Rats will selfadminister intravenous (i.v.) nicotine and will decrease their nicotine infusions when given a $\mathrm{nAChR}$ antagonist into the VTA, or DA antagonist into the NAc (Corrigall and Coen, 1989a,1991; Corrigall et al, 1994; Corrigall et al, 1989b; Exley et al, 2011; Maskos et al, 2005; Tolu et al, 2012). Grenhoff et al, 1986 were the first to show that i.p. nicotine $(0.5 \mathrm{mg} / \mathrm{kg})$ increases the in vivo burst activity of VTA DA neurons of anesthetized rats. In a brain-slice preparation of rat VTA DA neurons that were identified as dopaminergic with classic electrophysiological criteria of inhibition with DA bath application, investigators discovered that $10-100 \mu \mathrm{M}$ concentrations of nicotine caused increased depolarization, firing rate and inward current in a subset of neurons (77\%) recorded, yet $100 \%$ of them responded to acetylcholine's ability to increase depolarization, firing rate, and inward current (Calabresi et al, 1989). In this study, investigators further discovered that the increase in neural activity occurred in the presence of tetrodotoxin (TTX) and cobalt, confirming that the increase in neural activity can be due to direct actions of nicotine on a subset of VTA DA cells and not just through synaptic modulation (Figure 5).

VTA DA neurons express primarily $\alpha 2-\alpha 7$ and $\beta 2-\beta 4$ subunits (Klink et al, 2001; Pidoplichko et al, 1997). $\beta 2$-containing $\mathrm{nAChRs}$ in VTA DA neurons have a high affinity for nicotine, a long desensitization rate and exhibit a strong upregulation during chronic nicotine exposure (Changeux, 2010). VTA DA neurons also express the low affinity $\alpha 7$-containing nAChRs, which are more permeable to calcium and may mediate synaptic transmission more than other nAChRs (McGehee and Role, 1995; Seguela et al, 1993). Studies performed on transgenic mice have tried to identify the particular nAChRs subunits that encode the reinforcing properties of nicotine (Changeux, 2010; Pons et al, 2008; Reperant et al, 2010). In particular, VTA $\beta 2$ containing nAChRs have been demonstrated to be key modulators of nicotine's positive reinforcing properties and effects on VTA DA bursting (Faure et al, 2014). Mice with a $\beta 2-\mathrm{KO}$ will not self-administer nicotine (Picciotto et $a l, 1998)$. Reintroducing the $\beta 2$-subunit into the VTA with specific lentiviruses in $\beta 2-\mathrm{KO}$ mice restores nicotine's reinforcing properties (Mameli-Engvall et al, 2006; Maskos et al, 2005; Tolu et al, 2012). In addition, genome-wide association studies identified a human polymorphism of nAChRs with $\alpha 3, \alpha 5$, and $\beta 4$ subunits that may underlie a risk for increased nicotine intake and addiction (Wang et al, 2009). Knocking out $\alpha 5$-subunits in VTA DA neurons caused nicotine's excitatory effects in vivo to only occur at higher concentrations of nicotine and mimicking this $\alpha 5$-subunit polymorphism in mice led to increased self-administration of nicotine (Morel et al, 2013).

An important attribute to heteromeric nAChRs is the rate of desensitization each subunit contributes to, which could contribute to nicotine's strong craving effects. Using a wholecell electrophysiological assay with nicotine concentrations in a physiological range, Pidoplichko et al demonstrated that bath application of 0.1 or $0.5 \mu \mathrm{M}$ nicotine onto VTA DA neurons in an acute slice preparation, which exhibited $\mathrm{TH}$ and $I_{\mathrm{h}}$, rapidly induced increased depolarization, firing rate and inward current (Henningfield et al, 1993; Pidoplichko et al, 1997). Interestingly, these investigators discovered that during the bath application of $0.5 \mu \mathrm{M}$ nicotine, brief acetylcholine pulses, which would normally induce inward currents, were significantly reduced with a downward shift in baseline current suggesting a hyperpolarization of the VTA DA neurons and ultimately a desensitization. After a $1 \mathrm{~min}$ bath application, acetylcholine's ability to induce action potentials was also reduced, suggesting a larger desensitization of nAChRs. During a longer bath application (19 min), nicotine caused stronger desensitization to acetylcholine pulses, causing a return to original resting membrane potential, baseline current, and blockade of acetylcholineinduced action potentials. This study showed physiologically relevant mechanisms of nicotinic action on VTA DA neurons, and investigated the role of desensitization in $\mathrm{nAChR}$ regulation of dopaminergic activity. This desensitization of dopaminergic activity has been hypothesized to contribute to nicotine craving (Pidoplichko et al, 1997).

Researchers have also been focused on how nicotine modulates synaptic transmission onto VTA DA neurons. Although low concentrations of nicotine are enough to stimulate VTA dopaminergic activity intrinsically via nAChRs, particularly through high-affinity nAChRs, this mechanism is not enough to explain how a single injection of nicotine can result in increased DA release in downstream regions lasting for more than an hour (Di Chiara and Imperato, 1988). Interestingly, a single injection of nicotine can cause an increase in the AMPA/NMDA ratio on VTA DA neurons, suggesting a glutamatergic mechanism of nicotine-induced synaptic plasticity (Figure 5) (Saal et al, 2003). nAChRs are expressed on both presynaptic glutamatergic terminals in the VTA and post-synaptically on VTA 
DA neurons, and are key mediators of glutamatergic LTP (Laviolette and van der Kooy, 2004; Mansvelder et al, 2002a). Calcium-permeable $\alpha 7$-containing nAChRs expressed on presynaptic glutamatergic terminals can induce high calcium influxes to potentiate neurotransmitter release and facilitate synaptic strengthening (glutamatergic LTP) (Figure 5) (Seguela et al, 1993). Picciotto et al, 1998 hypothesized that the mechanisms underlying the downregulation of selfadministration in $\beta 2-\mathrm{KO}$ mice could be due to a lack of a functional depolarization with nicotine, which may weaken NMDA receptor mediated glutamatergic LTP.

Nicotine also activates GABA neurons, including GABAergic projections to the VTA DA neurons and VTA GABA interneurons, through nAChRs with $\alpha 7$ and $\alpha 4 \beta 2$-subunits (Figure 5) (Faure et al, 2014). There are a number of mechanisms by which nicotine acts on GABA afferent inputs, VTA GABA interneurons and VTA DA neurons to ultimately increase DA release have been proposed. Here we will briefly discuss two separate hypotheses: the disinhibition of GABA; and the coactivation of VTA DA and GABA neurons in response to nicotine. Bath application of $1 \mu \mathrm{M}$ of nicotine while recording from $I_{\mathrm{h}}$-positive VTA DA neurons in vitro, using horizontal VTA slices that preserve GABAergic afferents from the NAc and VP, caused increases in IPSC frequency and amplitude, followed by a decrease in frequency in seven out of 11 neurons (Mansvelder et al, 2002a). This suggests a desensitization of nicotine on GABA neurons and thus a reduction in inhibitory tone (Mansvelder et al, 2002a). The combination of desensitization of GABA tone on a subpopulation of VTA DA neurons, increased glutamate potentiation and a shift to a depolarized state is thought to then shift the major regulatory control of VTA DA neurons to an excitatory state, resulting in prolonged DA release onto downstream targets (Mansvelder et al, 2002a). Recently, however, a mechanism identifying coactivation of VTA GABA and DA neurons has been proposed to also increase VTA DA neuron firing and nicotine reinforcement. Anesthetized in vivo recordings in mice demonstrated that VTA GABA interneurons do not desensitize to repeated i.v. injections of nicotine $(30 \mu \mathrm{g} / \mathrm{kg}$, an acutely rewarding dose), and that a balance between excitation on both VTA GABA and DA populations shape VTA DA neuron bursting (Tolu et al, 2013). These two studies suggest alternate mechanisms of GABAergic regulation of VTA DA neurons based on GABA source (afferents from outside substrate $v s$ interneurons in VTA), which highlights the importance of studying specific circuit regulation of subpopulations of VTA DA neurons.

Studies have shown strong heterogeneity in response to nicotine in VTA DA neurons that could be due to intrinsic composition of nAChRs or differential synaptic inputs from a number of cortical and cortical regions (Figure 2) (Ikemoto, 2007; Ikemoto et al, 2006). A discovery made by Calabresi et al, 1989 demonstrated that less than one third of classically identified VTA DA neurons did not respond to nicotine, which highlights not only the functional diversity of VTA dopaminergic subpopulations, but also the mixed distribution of nAChRs across the VTA. In addition, Pidoplichko et al, 1997 discovered that there is large variability in post-nicotine depolarization recovery, acetycholine-induced currents with nicotine bath application.
There seems to be consistent anatomical, possibly projection-specific, disparities in nicotinic responses. Posterior VTA DA neurons display higher activation in response to nicotine than anterior VTA DA neurons (Li et al, 2011). In addition, a subset of dorsally located mVTA DA neurons was found to be inhibited by i.v. nicotine $(15-90 \mu \mathrm{g} / \mathrm{kg})$ via D2 receptor activation, while more ventral-laterally located VTA DA neurons were excited (Eddine et al, 2015). Methodical investigations into determining whether projection-specific subpopulations of VTA DA neurons differentially express nAChR subunits could further elucidate the role regionspecific dopaminergic signaling has in nicotine reward.

\section{Opioid Modulation of VTA Dopamine Firing via Disinhibition}

The endogenous opioid system is composed of internally synthesized opioid peptides that bind to opioid receptors to regulate pain, reward, and stress. Opiates, such as morphine, and opioids, such as heroin, use this endogenous system to mediate their addictive qualities. Of particular interest to the opiate/opioid drug addiction field are MORs. MORs are expressed in a somatodendritic and presynaptic manner and are thought to inhibit neuronal activity either hyperpolarization via GIRKs on the membrane or through attenuation of presynaptic vesicular release (Fields and Margolis, 2015). Morphine and heroin act as agonists to MORs to induce their neurophysiological effects. MORs expressed in the VTA, of which $\beta$-endorphins have a high affinity for, are crucial to the encoding of a rewarding or hedonic state. Rats will ICSA MOR agonists into the VTA (Bozarth and Wise, 1981a,b). Additionally, systemically administered morphine needs an intact VTA to produce CPP (Olmstead and Franklin, 1997). Systemic administration of morphine or direct infusion of morphine into the VTA both cause DA release in the NAc (Di Chiara and Imperato, 1988; Leone et al, 1991).

Although the VTA's role in mediating morphine reward related behaviors is complicated, especially in opiate selfadministration (Gratton, 1996), investigators have sought to understand the actions morphine has on VTA DA neuron activity. Increased release of DA in the NAc after morphine is associated with increased in vivo spontaneous activity and bursting activity of VTA DA neurons (Gysling and Wang, 1983; Koo et al, 2012). Interestingly, investigators identified a population of non-DA cells in the VTA that were suppressed in activity following the morphine administration, which led them to hypothesize that morphine's actions to increase VTA DA activity was indirectly mediated by the suppression of non-DA cells in the VTA (Figure 5) (Gysling and Wang, 1983). In these studies, the investigators identified 'principal cells' that experienced D2 receptor mediated autoinhibition and that were nonresponsive to [met $\left.{ }^{5}\right]$-enkephalin. 'Secondary cells' were thought to be non-DA interneurons because they showed a very narrow action potential waveform and had the opposite response to DA and [met ${ }^{5}$-enkephalin that principal cells displayed. The hyperpolarization observed by secondary cells was found to be mediated by MORs and an increase in $\mathrm{K}^{+}$conductance. Activation of MORs caused a decrease in the frequency, but not amplitude, of spontaneous IPSCs on VTA DA neurons and, this in turn increased the spontaneous activity of VTA DA neurons. More recently, 
investigators have further confirmed that this populations of VTA GABA neurons either undergo a somatodendritic hyperpolarization via $\mathrm{MOR}$ activation of $\mathrm{K}^{+}$current to reduce VTA GABA firing or they undergo presynaptic terminal inhibition (Johnson and North, 1992a; Steffensen et al, 2006). Opioid inhibition of GABA signaling onto VTA DA neurons is not exclusive to VTA GABA interneurons. By virally expressing ChR2 in VP GABA afferents into the VTA, investigators found that light-activated IPSCs on VTA DA neurons were inhibited with MOR agonists. In addition, in vitro recordings from retrograde fluorescent beads, that identify VP-VTA GABA neurons, revealed that this GABAergic substrate found to be critical to tonic inhibition of VTA DA neurons in vivo is inhibited by MOR agonists (Hjelmstad et al, 2013).

The acute synaptic plasticity results of morphine on VTA DA neurons have since been investigated thoroughly, albeit using conventional ways to identify VTA DA neurons that might have tended to be specific for VTA-lsNAc neurons. Acute morphine treatment consistently enhances glutamatergic signaling in VTA DA neurons. A single injection of morphine increases the AMPA/NMDA ratio on VTA DA neurons (Figure 5) (Saal et al, 2003). A possible mechanism for this morphine-induced increase in AMPA/NMDA ratio could be because of the insertion of calcium-permeable, GluR2-lacking AMPA receptor subunits (Brown et al, 2011). In conjunction with this enhanced excitatory network, morphine also mediates GABAergic synaptic modulation. It was found that within VTA DA neurons that experience D2 receptor-mediated autoinhibition, LTP of GABA synapses (LTP-GABA) is decreased after morphine, a possible mechanism for the increased excitation of VTA DA neurons (Nugent et al, 2007). It was recently discovered that weakening GABA synapses through LTD (LTD-GABA) also weakened GABAergic transmission onto VTA DA neurons after a single injection of morphine (Dacher and Nugent, 2011a). Interestingly, morphine may provide a bidirectional control of synaptic plasticity (Dacher and Nugent, 2011b). The effects of chronic morphine have been studied less but are known to also induce plasticity mechanisms that induce reward seeking behaviors, particularly during withdrawal. These mechanisms are have been previously described comprehensively (Mazei-Robison and Nestler, 2012).

Morphine has been also shown to have heterogeneous responses in VTA DA neuron subpopulations that express distinct intrinsic properties and are modulated by differential afferents. These subpopulations of VTA DA neurons have been shown to display heterogeneous and sometimes opposite responses to morphine. When comparing VTA-NAc and VTA-BLA DA neurons, investigators found differential responses to [met ${ }^{5}$ ]-enkephalin MOR activation (Ford et al, 2006). Recently, subpopulations of VTA DA neurons have been identified to be either directly excited or directly inhibited MOR agonists in vitro (Margolis et al, 2014). Interestingly, Gysling and Wang, 1983 had observed a differential percent increase over baseline firing in VTA DA neurons after morphine administration. VTA DA neurons that had a slower baseline firing rate had larger percent increases than those cells that had a higher baseline firing rate. We now know that IVTA-lsNAc DA neurons exhibit slower firing frequencies than mVTA-mPFC, mVTA-BLA, and mVTA-cNAc neurons (Chaudhury et al, 2012; Lammel et al, 2008). If distinct subpopulations of VTA DA neurons do indeed have differential incremental increases in DA firing, this could result in different changes of DA concentrations in downstream targets of the VTA, helping tune behaviors in a finer manner.

The RMTg-VTA-lsNAc circuit is of interest for morphine actions as well. VTA DA neurons that project to the lsNAc are known to receive GABAergic modulation from the RMTg (see above). The GABA neurons in the RMTg express MORs in both their cell bodies and in their presynaptic terminals in the VTA (Sanchez-Catalan et al, 2014). These neurons are inhibited by morphine and MOR agonists (Lecca et al, 2011; Matsui et al, 2014; Matsui and Williams, 2011). The RMTg-VTA-lsNAc circuit could be a critical target for morphine's rewarding actions. Identifying other possible circuit-specific synaptic modulations of VTA DA neurons after acute morphine could be critical to understanding actions on plasticity.

\section{Cocaine's Actions through Dopamine Transporters and Synaptic Potentiation}

Cocaine mediates its effects on the mesolimbic DA system through its reinforcing and rewarding properties. Thus, much work has focused on how cocaine alters this system both acutely and following chronic administration and withdrawal. Cocaine dramatically modulates tonic DA levels in the terminal regions of VTA projections, primarily in the NAc, by binding to DATs and inhibiting its actions (Figure 5). Cocaine attenuates the reuptake of DA into presynaptic terminals and greatly prolongs its action on both D2 auto- and hetero-receptors. This uptake inhibition results in dramatically increased DA concentrations (Ferris et al, 2014; Giros et al, 1996; Sulzer, 2011). Furthermore, the ability of cocaine to inhibit DATs and elevate DA levels is drastically changed by a history of chronic cocaine history. However, there are contradictory reports of sensitization and tolerance directly at the DAT. Much of this has been attributed to the time course and pattern of cocaine concentrations in the blood between these two models and its effects on DAT function. These differences have been reviewed extensively in a recent publication (Siciliano et al, 2015).

In addition to the effects of cocaine on DATs, cocaine also has indirect effects on the presynaptic DA terminal in the NAc. Cocaine-induced elevations in synaptic DA levels also modulate D2-autoreceptor function by promoting their desensitization (Siciliano et al, 2015). D2-autoreceptor function is critical to inhibiting DA release and ultimately the regulation of DA tone. Repeated cocaine can result in compensatory alterations in this system that alter basal DA tone, resulting in a hypodopaminergic state where alterations in autoreceptor function and uptake rate produce reductions in DA tone. Interestingly, there is great heterogeneity in the expression and function of DATs and D2 receptors within the subpopulations of VTA DA neurons (Lammel et al, 2008). This differential expression of DATs and D2s could lead to the differential release and uptake dynamics in regions of the brain that are known to encode drug-related information for goal directed behaviors. 
Because cocaine inhibits uptake, it can potentiate the size and temporal profile of DA transients in VTA projection regions at the presynaptic level. However, in addition to increasing DA transients at the presynaptic level, cocaine also has potent abilities to alter glutamatergic and GABAergic synaptic plasticity on VTA DA neurons. A history of repeated cocaine injections has been shown to increase glutamate in the VTA in response to a cocaine challenge (Kalivas and Duffy, 1998). This increase in glutamate was found to be dependent on functional D1 receptors on glutamatergic afferents in the VTA and may be a key factor to glutamatergic synaptic enhancement on VTA DA neurons (Kalivas and Duffy, 1998). Furthermore, an ultrastructural analysis of glutamatergic terminals in the VTA found increased glutamatergic immunolabeling in cocaine sensitized mice as compared with acutely injected mice (Kozell and Meshul, 2001). In contrast, repeated cocaine injection induced a decrease in D1-mediated GABAergic transmission in the VTA that was regulated by adenosine receptors and cAMP modulation (Bonci and Williams, 1996).

Glutamatergic plasticity on VTA DA neurons is critical to the persistence of drug-seeking behaviors (Engblom et al, 2008). A single injection of cocaine was found to increase AMPA/NMDA ratio on conventionally identified VTA DA neurons $24 \mathrm{~h}$ after injection (Figure 5) (Ungless et al, 2001). Moreover, this single injection of cocaine occluded the induction of high-frequency LTP, suggesting that VTA DA neurons had undergone cocaine-induced LTP (Ungless et al, 2001). This effect lasts for 5 but not 10 days after the single injection and was mediated by increased AMPA receptormediated currents (Ungless et al, 2001). A decrease in NMDA receptor-mediated currents was also discovered after a single injection of cocaine and predicted increased inward rectification and increased AMPA receptor-mediated currents, possibly through the insertion of calcium-permeable AMPA subunits (Mameli et al, 2011). The importance of cocaine-induced glutamatergic synaptic plasticity in the VTA is further confirmed by a study that discovered that blocking ionotropic glutamate receptors in the VTA prevents the formation of cocaine CPP (Harris and Aston-Jones, 2003).

Chronic cocaine exerts intrinsic and synaptic plasticity changes across VTA DA neurons. Foundational work discovered that chronic cocaine $(10 \mathrm{mg} / \mathrm{kg}$ twice daily i.p. injections for 14 days) reduced D2-mediated autoinhibition of VTA DA neurons and increased the number of spontaneously active VTA DA neurons in vivo (Henry et al, 1989). Investigators discovered that repeated (5-7 days) in vivo cocaine administration $(15 \mathrm{mg} / \mathrm{kg})$ in rats facilitates NMDA receptor-mediated LTP induction in VTA DA neurons that exhibit a large $I_{\mathrm{h}}$ (Liu et al, 2005). This induction of LTP following repeated cocaine administration was caused by a reduction of $\mathrm{GABA}_{\mathrm{A}}$ receptor activity, as determined by the reduction of the amplitude of GABAmediated currents (Liu et al, 2005). These findings suggest that chronic cocaine results in decreased GABAergic inhibition of VTA DA neurons. Withdrawal (10-15 days) from the same regimen of repeated cocaine administration allowed for the induction of NMDA receptor mediated LTP after weak presynaptic stimulations, which was not observed in saline-treated rats or cocaine-treated rats that experienced a $24 \mathrm{~h}$ withdrawal. This suggests a sensitization of VTA DA neurons following withdrawal ( $\mathrm{Pu}$ et al, 2006). Interestingly, brain-derived neurotrophic factor (BDNF) was found to be a critical mediator of this sensitivity. Bath application of BDNF onto VTA slices before, but not during, weak presynaptic stimulations facilitated LTP of VTA DA neurons in salinetreated rats and rats that had experienced only $24 \mathrm{~h}$ of withdrawal, an effect that was further determined to be dependent on BDNF's effects post-synaptically and was occluded in rats that had 10-15 days of withdrawal postsynaptically as well ( $\mathrm{Pu}$ et al, 2006).

Current research has identified heterogeneous responses to cocaine to parse out the subpopulations of VTA DA neurons mediating the rewarding properties of cocaine. It was demonstrated that i.v. injection of cocaine in anesthetized rats induced a partial inhibition of activity in VTA DA neurons that were identified to project to the NAc (Einhorn et al, 1988). However, it was also observed that in vivo injections of cocaine in awake rats differentially altered the activity of VTA DA neurons, with only $14 \%$ exhibiting a decrease of firing rate and bursting activity and a significant percent of the population experiencing an increase in activity (Koulchitsky et al, 2012). Recently, in a thorough anatomical and immunohistochemical investigation, investigators identified that a majority of VTA DA neurons that were inhibited by cocaine resided in the posterior VTA, while those that were excited were more anterior in the VTA during anesthetized in vivo recordings (Mejias-Aponte et al, 2015).

In addition, it was discovered that one injection of cocaine-induced increases in AMPA/NMDA ratios $24 \mathrm{~h}$ later, in VTA DA neurons that specifically project to the lsNAc and msNAc (Lammel et al, 2011). Interestingly, the changes observed in those VTA DA neurons that project to the msNAc were persistent up to 21 days after single cocaine injection, which correlates with findings of larger increases in DA concentrations in the msNAc (Aragona et al, 2008). Surprisingly, no changes in synaptic strength were observed in VTA DA neurons that project to the mPFC; however, changes were observed in this projection after an aversive formalin injection into the paw (Lammel et al, 2011). Based on circuit tracing studies, we now know specific afferent inputs could underlie these differential stimulus responses. In vivo modulation of differential glutamatergic afferent inputs onto VTA DA neurons using optogenetically induced LTP/LTD or using designer receptors exclusively activated by designer drugs to alter dopaminergic activity following cocaine injection would provide more insight into how circuit-specific actions lead to cocaine-induced drug plasticity.

\section{HYPOCRETINS ACT AS NEUROMODULATORS OF DRUG-INDUCED PLASTICITY ON VTA DOPAMINE NEURONS}

Hcrts has an important role in mediating the associative and cue-induced reinstatement properties of multiple classes of drugs, including alcohol, morphine, and cocaine. Transgenic mice that have a KO of the prepro-hcrt gene do not establish a CPP to cocaine (Narita et al, 2006). Systemic injections of the hcrtR1 antagonist SB-334867 (SB) before the test session of morphine CPP show reduced preference for the morphine conditioned side, demonstrating hort involvement in behaviors involving drug associations (Harris et al, 2005). Hcrt is also important for cue-induced drug reinstatement following 
extinction. Systemic blockade of hcrtR1-reduced ethanol seeking and cocaine seeking (Lawrence et al, 2006; Smith et al, 2009). The VTA is a critical neural substrate for modulating these actions. Infusion of $\mathrm{SB}$ into the VTA directly reduced morphine CPP (Narita et al, 2006). In addition, LH-VTA neurons were demonstrated to have robust correlations of c-fos induction with morphine CPP (Aston-Jones et al, 2009a; Aston-Jones et al, 2009b). These investigations found no differences in LH projections that preferentially synapse in the rostral or caudal VTA.

Hcrts are important mediators of synaptic plasticity on VTA DA neurons. Borgland et al have consistently demonstrated a crucial role for hcrtR1 in mediating drug-induced synaptic actions. To note, these studies have used the conventional criteria of DA neuron identification for their studies. Using a hcrtR-1 antagonist before cocaine injections for 5 days was shown to block cocaine's potentiation of the AMPA/NMDA ratio and is also critical to the induction of the locomotor sensitization effects of cocaine (Borgland et al, 2006). Recently, it was discovered that hortR1 is also critical for the synaptic actions observed following morphine administration. Blockade of hcrtR1 on VTA DA neurons prevents AMPA/NMDA potentiation, prevents morphineinduced increases in AMPA receptor-mediated current frequency and amplitude, and also prevents morphineinduced increases in presynaptic glutamate release (Baimel and Borgland, 2015). Interestingly, in the same study, they also discovered that hcrtR1 was important for the morphineinduced decreases in GABA release onto VTA DA neurons (Baimel and Borgland, 2015).

Modulation of hort signaling seems critical for the druginduced increases of DA in downstream targets. Morphine's ability to increase DA release in the NAc is reduced in prepro-hcrt KO mice (Narita et al, 2006). Infusion of hcrt1 directly into the VTA potentiated the cocaine-induced DA release in the NAc (Espana et al, 2010). Concurrently, blockade of hcrtR1 decreased this release (Espana et al, 2010). Investigations into the projection-specific expression of hcrt-Rs would be critical in understanding how different subpopulations of VTA DA neurons are modulated by their differential synaptic inputs, particularly on VTA DA neurons that project to the mPFC or the BLA.

\section{STRESS AND DRUG INTERACTIONS}

Stressful events are known to enhance the reinforcing properties of drugs and influence drug-seeking behaviors in both humans and non-human animal models (Erb et al, 1996; Kalivas and McFarland, 2003; Piazza and Le Moal, 1996; Sanchis-Segura and Spanagel, 2006). Interestingly, withdrawal from drugs of abuse is known to activate neural circuits associated with stress response and has been thoroughly reviewed elsewhere (Koob, 2008; Koob et al, 2014). However, here we will focus on how the experience of a stressful or aversive can cause alterations for the mesocorticolimbic system to influence drug-associated behaviors and drug-induced plasticity.

Mild stressors, such as footshock or food restriction, have been shown to cause larger reinforcement of heroin, increased cocaine sensitization and higher cocaine CPP (Goeders and Guerin, 1994; McLaughlin et al, 2003; Rouge-Pont et al,
1995; Shaham and Stewart, 1994). Furthermore, psychological stressors, such as social isolation, restraint stress, or social defeat stress, can increase administration of drugs of abuse (Croft et al, 2005; Schenk et al, 1985; Shaham, 1993). The VTA has been identified as an important mediator of these behaviors through a number of means that include interaction of VTA DA neurons with CRF, GCCs, and differential synaptic inputs that are responsive to stress. Importantly, the VTA is critical for stress-induced reinstatement of drugseeking behavior (Graziane et al, 2013; McFarland et al, 2004). Further understanding how both stressful stimuli and drug-induced plasticity mechanisms converge on VTA DA neurons is critical. Indeed, recently, investigators discovered that VTA DA neurons that were excited by cocaine administration were also more likely to be responsive to a typically aversive footshock stimulus (Mejias-Aponte et al, 2015).

One way that stress can affect drug-induced plasticity is through the stress-related neuropeptide, CRF. CRF influences VTA DA activity and is a regulator of plasticity (see above). Blockade of CRF-R1 in the VTA prevents cocaine-induced DA increases in the NAc (Lodge and Grace, 2005). Mild footshock induces reinstatement of DA activation with glutamate release and CRF release in the VTA in cocaine-experienced animals (Wang et al, 2005). CRF-Rs and CRF-BP have been shown to be critical in the VTA since non-specific antagonism of both receptors prevents footshock events, and CRF's effects to potentiate glutamatergic NMDA receptor currents is dependent on CRF-R2 and CRF-BP function (Ungless et al, 2003; Wang et al, 2007). However, there have been reports suggesting that cocaine experience is necessary to induce long-lasting changes in plasticity for stress or CRF to have its reinstatement actions (Wise and Morales, 2009). Yet, mice that binge drink alcohol undergo CRF-R1 mediated NMDA receptor current enhancement, suggesting an acute action from binging (Sparta et al, 2013). The differential expression of the two CRF receptors in the VTA also calls into the question: which subpopulations of VTA DA neurons are mediating these aversive events? CRF was shown to have D2 autoreceptor desensitization actions in the subpopulation of VTA DA neurons that express D2, leaving a subpopulation to be investigated for other possible CRF intrinsic actions (Nimitvilai et al, 2014).

Stressful events can trigger the synthesis and release of GCCs, which have actions on the mesocorticolimbic system (see above). GCCs released during stress have also been shown to be influential in the reinforcing properties of drugs of abuse as well as in relapse behaviors. Blocking corticosterone synthesis during stressful food restrictions was found to block sensitization to cocaine and morphine, suggesting a GCC role in inducing susceptibility to drug reward (Deroche et al, 1992; Rouge-Pont et al, 1995). Indeed, there have been many investigations exploring the mechanisms by which GCCs mediate individual vulnerabilities to drug reinforcement, which have been reviewed (Piazza and Le Moal, 1996). Morphine's actions in the VTA to induce locomotor responses were also demonstrated to be dependent on GR signaling (Marinelli et al, 1998). GCC modulation of afferent plasticity in coherence with druginduced synaptic plasticity could be a critical mediator of enhanced behavioral responses to drugs of abuse. 
The VTA, with its inputs from cortical and subcortical structures, acts as a hub for a number of neural afferents that converge to encode information about intrinsic and external states. As stated above, many researchers are discovering input-specific control of subpopulations of VTA DA neurons. Studies that investigate how differential afferents regulate VTA DA response in the face of stress experience and drug use are now crucial. Since Lammel et al's work suggest that $\mathrm{mPFC}$ and lsNAc, but not msNAc, projecting VTA DA neurons act as substrates for encoding different stimuli, it would be interesting to see how a convergence of typically rewarding (drugs of abuse) and aversive stimuli alter plasticity mechanisms. One source of afferent control is the vSub, which is thought to be an important neural substrate in the activation of VTA DA neurons in contextually relevant situations due to its influence on VTA DA neuron population activity (Belujon and Grace, 2015). Acute restraint stress causes sensitization to psychomotor effects of the psychostimulant, amphetamine, concurrent with increases in VTA DA neuron population activity, which is known to be disinhibited by the vSubNAc-VP-VTA circuit (Valenti et al, 2011). This increase in VTA DA activity is dependent on the vSub input (Belujon and Grace, 2011; Valenti et al, 2011). Recently, a new vSub circuit linking the vSub-BNST-VTA circuit was identified to be critical in cocaine's locomotor affects and in the induction of increased activity in a subpopulation of VTA DA neurons (Glangetas et al, 2015). Further investigation into how relay circuits of fast-acting neurotransmitters work in conjunction with stress- and drug-responsive neuromodulators would also elucidate neural circuit mechanisms of stress contextassociated drug-induced plasticity in the VTA.

\section{DISCUSSION}

We have reviewed the distinct subpopulations of projecting VTA DA neurons, the differential drug-induced plasticity mechanisms on VTA DA neurons and highlighted the necessity for a better understanding of these mechanisms across all subpopulations of VTA DA neurons. The mesocorticolimbic system is a critical mediator of drug abuse. However, the VTA sends functionally distinct DA projections to its targets. Recent advances in circuit dissecting techniques, projection- and cell-specific molecular profiling and in vivo imaging of cell projection-specific neuronal activity have opened up new avenues into addressing these issues. In addition, the call for better transgenic mouse lines that allow for dopaminergic specific expression of GFP or Cre-recombinase will help the field further.

\section{FUNDING AND DISCLOSURE}

The authors declare no conflict of interest.

\section{ACKNOWLEDGMENTS}

We thank Stacy Ku and Drs Carole Morel, Peter Rudebeck, and Erin S. Calipari for their helpful guidance and review of these topics. This work was supported by the National
Institute on Alcohol Abuse and Alcoholism (R01 AA022445, MHH; F31 AA022862, BJ).

\section{REFERENCES}

Anstrom KK, Woodward DJ (2005). Restraint increases dopaminergic burst firing in awake rats. Neuropsychopharmacology 30: 1832-1840.

Aragona BJ, Cleaveland NA, Stuber GD, Day JJ, Carelli RM, Wightman RM (2008). Preferential enhancement of dopamine transmission within the nucleus accumbens shell by cocaine is attributable to a direct increase in phasic dopamine release events. J Neurosci 28: 8821-8831.

Aryal P, Dvir H, Choe S, Slesinger PA (2009). A discrete alcohol pocket involved in GIRK channel activation. Nat Neurosci 12: 988-995.

Aston-Jones G, Smith RJ, Moorman DE, Richardson KA (2009a). Role of lateral hypothalamic orexin neurons in reward processing and addiction. Neuropharmacology 56(Suppl 1): 112-121.

Aston-Jones G, Smith RJ, Sartor GC, Moorman DE, Massi L, Tahsili-Fahadan P et al (2009b). Lateral hypothalamic orexin/ hypocretin neurons: a role in reward-seeking and addiction. Brain Res 1314: 74-90.

Baimel C, Borgland SL (2015). Orexin signaling in the VTA gates morphine-induced synaptic plasticity. J Neurosci 35: 7295-7303.

Bannon MJ, Roth RH (1983). Pharmacology of mesocortical dopamine neurons. Pharmacol Rev 35: 53-68.

Barik J, Marti F, Morel C, Fernandez SP, Lanteri C, Godeheu G et al (2013). Chronic stress triggers social aversion via glucocorticoid receptor in dopaminoceptive neurons. Science 339: 332-335.

Barrot M (2014). The ventral tegmentum and dopamine: a new wave of diversity. Neuroscience 282C: 243-247.

Barrot M, Marinelli M, Abrous DN, Rouge-Pont F, Le Moal M, Piazza PV (2000). The dopaminergic hyper-responsiveness of the shell of the nucleus accumbens is hormone-dependent. Eur $J$ Neurosci 12: 973-979.

Beckstead MJ, Grandy DK, Wickman K, Williams JT (2004). Vesicular dopamine release elicits an inhibitory postsynaptic current in midbrain dopamine neurons. Neuron 42: 939-946.

Beier KT, Steinberg EE, DeLoach KE, Xie S, Miyamichi K, Schwarz L et al (2015). Circuit architecture of VTA dopamine neurons revealed by systematic input-output mapping. Cell 162: 622-634.

Belujon P, Grace AA (2011). Hippocampus, amygdala, and stress: interacting systems that affect susceptibility to addiction. Ann N Y Acad Sci 1216: 114-121.

Belujon P, Grace AA (2015). Regulation of dopamine system responsivity and its adaptive and pathological response to stress. Proc Biol Sci 282.

Berger B, Di Porzio U, Daguet MC, Gay M, Vigny A, Glowinski J et al (1982). Long-term development of mesencephalic dopaminergic neurons of mouse embryos in dissociated primary cultures: morphological and histochemical characteristics. Neuroscience 7: 193-205.

Bilder RM, Volavka J, Lachman HM, Grace AA (2004). The catechol-O-methyltransferase polymorphism: relations to the tonic-phasic dopamine hypothesis and neuropsychiatric phenotypes. Neuropsychopharmacology 29: 1943-1961.

Bodhinathan K, Slesinger PA (2014). Alcohol modulation of G-protein-gated inwardly rectifying potassium channels: from binding to therapeutics. Front Physiol 5: 76.

Bonci A, Williams JT (1996). A common mechanism mediates long-term changes in synaptic transmission after chronic cocaine and morphine. Neuron 16: 631-639.

Borgland SL, Taha SA, Sarti F, Fields HL, Bonci A (2006). Orexin A in the VTA is critical for the induction of synaptic plasticity and behavioral sensitization to cocaine. Neuron 49: 589-601. 
Boulter J, Connolly J, Deneris E, Goldman D, Heinemann S, Patrick J (1987). Functional expression of two neuronal nicotinic acetylcholine receptors from cDNA clones identifies a gene family. Proc Natl Acad Sci USA 84: 7763-7767.

Bozarth MA, Wise RA (1981a). Heroin reward is dependent on a dopaminergic substrate. Life Sci 29: 1881-1886.

Bozarth MA, Wise RA (1981b). Intracranial self-administration of morphine into the ventral tegmental area in rats. Life Sci 28: 551-555.

Brischoux F, Chakraborty S, Brierley DI, Ungless MA (2009). Phasic excitation of dopamine neurons in ventral VTA by noxious stimuli. Proc Natl Acad Sci USA 106: 4894-4899.

Brodie MS (2002). Increased ethanol excitation of dopaminergic neurons of the ventral tegmental area after chronic ethanol treatment. Alcohol Clin Exp Res 26: 1024-1030.

Brodie MS, Pesold C, Appel SB (1999). Ethanol directly excites dopaminergic ventral tegmental area reward neurons. Alcohol Clin Exp Res 23: 1848-1852.

Brodie MS, Scholz A, Weiger TM, Dopico AM (2007). Ethanol interactions with calcium-dependent potassium channels. Alcohol Clin Exp Res 31: 1625-1632.

Brodie MS, Shefner SA, Dunwiddie TV (1990). Ethanol increases the firing rate of dopamine neurons of the rat ventral tegmental area in vitro. Brain Res 508: 65-69.

Brown MT, Bellone C, Mameli M, Labouebe G, Bocklisch C, Balland B et al (2011). Drug-driven AMPA receptor redistribution mimicked by selective dopamine neuron stimulation. PLoS One 5: e15870.

Calabresi P, Lacey MG, North RA (1989). Nicotinic excitation of rat ventral tegmental neurones in vitro studied by intracellular recording. Br J Pharmacol 98: 135-140.

Cao JL, Covington HE 3rd, Friedman AK, Wilkinson MB, Walsh JJ, Cooper DC et al (2010). Mesolimbic dopamine neurons in the brain reward circuit mediate susceptibility to social defeat and antidepressant action. J Neurosci 30: 16453-16458.

Carr DB, Sesack SR (2000a). GABA-containing neurons in the rat ventral tegmental area project to the prefrontal cortex. Synapse 38: 114-123.

Carr DB, Sesack SR (2000b). Projections from the rat prefrontal cortex to the ventral tegmental area: target specificity in the synaptic associations with mesoaccumbens and mesocortical neurons. J Neurosci 20: 3864-3873.

Changeux JP (2010). Nicotine addiction and nicotinic receptors: lessons from genetically modified mice. Nat Rev Neurosci 11: 389-401.

Chaudhury D, Walsh JJ, Friedman AK, Juarez B, Ku SM, Koo JW et al (2012). Rapid regulation of depression-related behaviours by control of midbrain dopamine neurons. Nature 493: 532-536.

Chergui K, Charlety PJ, Akaoka H, Saunier CF, Brunet JL, Buda M et al (1993). Tonic activation of NMDA receptors causes spontaneous burst discharge of rat midbrain dopamine neurons in vivo. Eur J Neurosci 5: 137-144.

Chiodo LA, Bannon MJ, Grace AA, Roth RH, Bunney BS (1984). Evidence for the absence of impulse-regulating somatodendritic and synthesis-modulating nerve terminal autoreceptors on subpopulations of mesocortical dopamine neurons. Neuroscience 12: 1-16.

Clements JR, Grant S (1990). Glutamate-like immunoreactivity in neurons of the laterodorsal tegmental and pedunculopontine nuclei in the rat. Neurosci Lett 120: 70-73.

Corrigall WA, Coen KM (1989a). Nicotine maintains robust selfadministration in rats on a limited-access schedule. Psychopharmacology (Berl) 99: 473-478.

Corrigall WA, Coen KM (1991). Selective dopamine antagonists reduce nicotine self-administration. Psychopharmacology (Berl) 104: 171-176.

Corrigall WA, Coen KM, Adamson KL (1994). Self-administered nicotine activates the mesolimbic dopamine system through the ventral tegmental area. Brain Res 653: 278-284.
Corrigall WA, Herling S, Coen KM (1989b). Evidence for a behavioral deficit during withdrawal from chronic nicotine treatment. Pharmacol Biochem Behav 33: 559-562.

Couturier S, Bertrand D, Matter JM, Hernandez MC, Bertrand S, Millar N et al (1990a). A neuronal nicotinic acetylcholine receptor subunit (alpha 7) is developmentally regulated and forms a homo-oligomeric channel blocked by alpha-BTX. Neuron 5: 847-856.

Couturier S, Erkman L, Valera S, Rungger D, Bertrand S, Boulter J et al (1990b). Alpha 5, alpha 3, and non-alpha 3. Three clustered avian genes encoding neuronal nicotinic acetylcholine receptorrelated subunits. J Biol Chem 265: 17560-17567.

Croft AP, Brooks SP, Cole J, Little HJ (2005). Social defeat increases alcohol preference of C57BL/10 strain mice; effect prevented by a CCKB antagonist. Psychopharmacology (Berl) 183: 163-170.

Dacher M, Nugent FS (2011a). Morphine-induced modulation of LTD at GABAergic synapses in the ventral tegmental area. Neuropharmacology 61: 1166-1171.

Dacher M, Nugent FS (2011b). Opiates and plasticity. Neuropharmacology 61: 1088-1096.

de Kloet ER, Joels M, Holsboer F (2005). Stress and the brain: from adaptation to disease. Nat Rev Neurosci 6: 463-475.

Deneris ES, Boulter J, Swanson LW, Patrick J, Heinemann S (1989). Beta 3: a new member of nicotinic acetylcholine receptor gene family is expressed in brain. J Biol Chem 264: 6268-6272.

Deroche V, Piazza PV, Casolini P, Maccari S, Le Moal M, Simon H (1992). Stress-induced sensitization to amphetamine and morphine psychomotor effects depend on stress-induced corticosterone secretion. Brain Res 598: 343-348.

Di Chiara G, Imperato A (1985). Ethanol preferentially stimulates dopamine release in the nucleus accumbens of freely moving rats. Eur J Pharmacol 115: 131-132.

Di Chiara G, Imperato A (1988). Drugs abused by humans preferentially increase synaptic dopamine concentrations in the mesolimbic system of freely moving rats. Proc Natl Acad Sci USA 85: 5274-5278.

Diana M, Pistis M, Carboni S, Gessa GL, Rossetti ZL (1993). Profound decrement of mesolimbic dopaminergic neuronal activity during ethanol withdrawal syndrome in rats: electrophysiological and biochemical evidence. Proc Natl Acad Sci USA 90: 7966-7969.

Ding ZM, Ingraham CM, Rodd ZA, McBride WJ (2014). The reinforcing effects of ethanol within the posterior ventral tegmental area depend on dopamine neurotransmission to forebrain cortico-limbic systems. Addict Biol 20: 458-468.

Eddine R, Valverde S, Tolu S, Dautan D, Hay A, Morel C et al (2015). A concurrent excitation and inhibition of dopaminergic subpopulations in response to nicotine. Sci Rep 5: 8184.

Einhorn LC, Johansen PA, White FJ (1988). Electrophysiological effects of cocaine in the mesoaccumbens dopamine system: studies in the ventral tegmental area. J Neurosci 8: 100-112.

Ekstrand MI, Nectow AR, Knight ZA, Latcha KN, Pomeranz LE, Friedman JM (2014). Molecular profiling of neurons based on connectivity. Cell 157: 1230-1242.

Engblom D, Bilbao A, Sanchis-Segura C, Dahan L, Perreau-Lenz S, Balland B et al (2008). Glutamate receptors on dopamine neurons control the persistence of cocaine seeking. Neuron 59: 497-508.

Erb S, Shaham Y, Stewart J (1996). Stress reinstates cocaine-seeking behavior after prolonged extinction and a drug-free period. Psychopharmacology (Berl) 128: 408-412.

Espana RA, Melchior JR, Roberts DC, Jones SR (2010). Hypocretin 1 /orexin $\mathrm{A}$ in the ventral tegmental area enhances dopamine responses to cocaine and promotes cocaine self-administration. Psychopharmacology (Berl) 214: 415-426.

Exley R, Maubourguet N, David V, Eddine R, Evrard A, Pons S et al (2011). Distinct contributions of nicotinic acetylcholine receptor subunit alpha4 and subunit alpha6 to the reinforcing effects of nicotine. Proc Natl Acad Sci USA 108: 7577-7582. 
Fadel J, Deutch AY (2002). Anatomical substrates of orexindopamine interactions: lateral hypothalamic projections to the ventral tegmental area. Neuroscience 111: 379-387.

Faure P, Tolu S, Valverde S, Naude J (2014). Role of nicotinic acetylcholine receptors in regulating dopamine neuron activity. Neuroscience 282C: $86-100$.

Ferris MJ, Espana RA, Locke JL, Konstantopoulos JK, Rose JH, Chen $\mathrm{R}$ et al (2014). Dopamine transporters govern diurnal variation in extracellular dopamine tone. Proc Natl Acad Sci USA 111: E2751-E2759.

Fields HL, Margolis EB (2015). Understanding opioid reward. Trends Neurosci 38: 217-225.

Floresco SB, West AR, Ash B, Moore H, Grace AA (2003). Afferent modulation of dopamine neuron firing differentially regulates tonic and phasic dopamine transmission. Nat Neurosci 6: 968-973.

Ford CP, Mark GP, Williams JT (2006). Properties and opioid inhibition of mesolimbic dopamine neurons vary according to target location. J Neurosci 26: 2788-2797.

Forster GL, Blaha CD (2000). Laterodorsal tegmental stimulation elicits dopamine efflux in the rat nucleus accumbens by activation of acetylcholine and glutamate receptors in the ventral tegmental area. Eur J Neurosci 12: 3596-3604.

Friedman AK, Walsh JJ, Juarez B, Ku SM, Chaudhury D, Wang J et al (2014). Enhancing depression mechanisms in midbrain dopamine neurons achieves homeostatic resilience. Science 344: 313-319.

Gariano RF, Groves PM (1988). Burst firing induced in midbrain dopamine neurons by stimulation of the medial prefrontal and anterior cingulate cortices. Brain Res 462: 194-198.

Garris PA, Collins LB, Jones SR, Wightman RM (1993). Evoked extracellular dopamine in vivo in the medial prefrontal cortex. J Neurochem 61: 637-647.

Gasbarri A, Packard MG, Campana E, Pacitti C (1994). Anterograde and retrograde tracing of projections from the ventral tegmental area to the hippocampal formation in the rat. Brain Res Bull 33: $445-452$.

Geisler S, Zahm DS (2005). Afferents of the ventral tegmental area in the rat-anatomical substratum for integrative functions. J Comp Neurol 490: 270-294.

Georges F, Aston-Jones G (2001). Potent regulation of midbrain dopamine neurons by the bed nucleus of the stria terminalis. J Neurosci 21: RC160.

Georges F, Aston-Jones G (2002). Activation of ventral tegmental area cells by the bed nucleus of the stria terminalis: a novel excitatory amino acid input to midbrain dopamine neurons. J Neurosci 22: 5173-5187.

Gessa GL, Muntoni F, Collu M, Vargiu L, Mereu G (1985). Low doses of ethanol activate dopaminergic neurons in the ventral tegmental area. Brain Res 348: 201-203.

Giros B, Jaber M, Jones SR, Wightman RM, Caron MG (1996). Hyperlocomotion and indifference to cocaine and amphetamine in mice lacking the dopamine transporter. Nature 379: 606-612.

Glangetas C, Fois GR, Jalabert M, Lecca S, Valentinova K, Meye FJ et al (2015). Ventral subiculum stimulation promotes persistent hyperactivity of dopamine neurons and facilitates behavioral effects of cocaine. Cell Rep 13: 2287-2296.

Goeders NE, Guerin GF (1994). Non-contingent electric footshock facilitates the acquisition of intravenous cocaine selfadministration in rats. Psychopharmacology (Berl) 114: 63-70.

Gogos JA, Morgan M, Luine V, Santha M, Ogawa S, Pfaff D et al (1998). Catechol-O-methyltransferase-deficient mice exhibit sexually dimorphic changes in catecholamine levels and behavior. Proc Natl Acad Sci USA 95: 9991-9996.

Gonzales C, Chesselet MF (1990). Amygdalonigral pathway: an anterograde study in the rat with Phaseolus vulgaris leucoagglutinin (PHA-L). J Comp Neurol 297: 182-200.
Gonzales RA, Job MO, Doyon WM (2004). The role of mesolimbic dopamine in the development and maintenance of ethanol reinforcement. Pharmacol Ther 103: 121-146.

Gotti C, Clementi F, Fornari A, Gaimarri A, Guiducci S, Manfredi I et al (2009). Structural and functional diversity of native brain neuronal nicotinic receptors. Biochem Pharmacol 78: 703-711.

Grace AA, Bunney BS (1983a). Intracellular and extracellular electrophysiology of nigral dopaminergic neurons-1. Identification and characterization. Neuroscience 10: 301-315.

Grace AA, Bunney BS (1983b). Intracellular and extracellular electrophysiology of nigral dopaminergic neurons-2. Action potential generating mechanisms and morphological correlates. Neuroscience 10: 317-331.

Grace AA, Bunney BS (1984a). The control of firing pattern in nigral dopamine neurons: burst firing. J Neurosci 4: 2877-2890.

Grace AA, Bunney BS (1984b). The control of firing pattern in nigral dopamine neurons: single spike firing. J Neurosci 4: 2866-2876.

Grace AA, Onn SP (1989). Morphology and electrophysiological properties of immunocytochemically identified rat dopamine neurons recorded in vitro. J Neurosci 9: 3463-3481.

Gratton A (1996). In vivo analysis of the role of dopamine in stimulant and opiate self-administration. J Psychiatry Neurosci 21: 264-279.

Graziane NM, Polter AM, Briand LA, Pierce RC, Kauer JA (2013). Kappa opioid receptors regulate stress-induced cocaine seeking and synaptic plasticity. Neuron 77: 942-954.

Grenhoff J, Aston-Jones G, Svensson TH (1986). Nicotinic effects on the firing pattern of midbrain dopamine neurons. Acta Physiol Scand 128: 351-358.

Grieder TE, Herman MA, Contet C, Tan LA, Vargas-Perez H, Cohen A et al (2014). VTA CRF neurons mediate the aversive effects of nicotine withdrawal and promote intake escalation. Nat Neurosci 17: 1751-1758.

Guan Y, Xiao C, Krnjevic K, Xie G, Zuo W, Ye JH (2012). GABAergic actions mediate opposite ethanol effects on dopaminergic neurons in the anterior and posterior ventral tegmental area. J Pharmacol Exp Ther 341: 33-42.

Guldberg HC, Marsden CA (1975). Catechol-O-methyl transferase: pharmacologica aspects and physiological role. Pharmacol Rev 27: 135-206.

Gysling K, Wang RY (1983). Morphine-induced activation of A10 dopamine neurons in the rat. Brain Res 277: 119-127.

Hamid AA, Pettibone JR, Mabrouk OS, Hetrick VL, Schmidt R, Vander Weele CM et al (2015). Mesolimbic dopamine signals the value of work. Nat Neurosci 19: 117-126.

Harris GC, Aston-Jones G (2003). Critical role for ventral tegmental glutamate in preference for a cocaine-conditioned environment. Neuropsychopharmacology 28: 73-76.

Harris GC, Wimmer M, Aston-Jones G (2005). A role for lateral hypothalamic orexin neurons in reward seeking. Nature 437: 556-559.

Henningfield JE, Stapleton JM, Benowitz NL, Grayson RF, London ED (1993). Higher levels of nicotine in arterial than in venous blood after cigarette smoking. Drug Alcohol Depend 33: 23-29.

Henry DJ, Greene MA, White FJ (1989). Electrophysiological effects of cocaine in the mesoaccumbens dopamine system: repeated administration. J Pharmacol Exp Ther 251: 833-839.

Hjelmstad GO, Xia Y, Margolis EB, Fields HL (2013). Opioid modulation of ventral pallidal afferents to ventral tegmental area neurons. J Neurosci 33: 6454-6459.

Hollander JA, Lu Q, Cameron MD, Kamenecka TM, Kenny PJ (2008). Insular hypocretin transmission regulates nicotine reward. Proc Natl Acad Sci USA 105: 19480-19485.

Hopf FW, Martin M, Chen BT, Bowers MS, Mohamedi MM, Bonci A (2007). Withdrawal from intermittent ethanol exposure increases probability of burst firing in VTA neurons in vitro. J Neurophysiol 98: 2297-2310. 
Huotari M, Gogos JA, Karayiorgou M, Koponen O, Forsberg M, Raasmaja A et al (2002). Brain catecholamine metabolism in catechol-O-methyltransferase (COMT)-deficient mice. Eur $J$ Neurosci 15: 246-256.

Hyman SE (2007). How mice cope with stressful social situations. Cell 131: 232-234.

Hyman SE, Malenka RC, Nestler EJ (2006). Neural mechanisms of addiction: the role of reward-related learning and memory. Annu Rev Neurosci 29: 565-598.

Ikemoto S (2007). Dopamine reward circuitry: two projection systems from the ventral midbrain to the nucleus accumbensolfactory tubercle complex. Brain Res Rev 56: 27-78.

Ikemoto S, Qin M, Liu ZH (2006). Primary reinforcing effects of nicotine are triggered from multiple regions both inside and outside the ventral tegmental area. J Neurosci 26: 723-730.

Jalabert M, Aston-Jones G, Herzog E, Manzoni O, Georges F (2009). Role of the bed nucleus of the stria terminalis in the control of ventral tegmental area dopamine neurons. Prog Neuropsychopharmacol Biol Psychiatry 33: 1336-1346.

Javoy-Agid F, Ploska A, Agid Y (1981a). Microtopography of tyrosine hydroxylase, glutamic acid decarboxylase, and choline acetyltransferase in the substantia nigra and ventral tegmental area of control and Parkinsonian brains. J Neurochem 37: 1218-1227.

Javoy-Agid F, Taquet H, Ploska A, Cherif-Zahar C, Ruberg M, Agid Y (1981b). Distribution of catecholamines in the ventral mesencephalon of human brain, with special reference to Parkinson's disease. J Neurochem 36: 2101-2105.

Jennings JH, Sparta DR, Stamatakis AM, Ung RL, Pleil KE, Kash TL et al (2013). Distinct extended amygdala circuits for divergent motivational states. Nature 496: 224-228.

Ji H, Hougaard C, Herrik KF, Strobaek D, Christophersen P, Shepard PD (2009). Tuning the excitability of midbrain dopamine neurons by modulating the Ca2+ sensitivity of SK channels. Eur J Neurosci 29: 1883-1895.

Ji H, Shepard PD (2006). SK Ca2+-activated K+ channel ligands alter the firing pattern of dopamine-containing neurons in vivo. Neuroscience 140: 623-633.

Johnson SW, North RA (1992a). Opioids excite dopamine neurons by hyperpolarization of local interneurons. I Neurosci 12: 483-488.

Johnson SW, Seutin V, North RA (1992b). Burst firing in dopamine neurons induced by $\mathrm{N}$-methyl-D-aspartate: role of electrogenic sodium pump. Science 258: 665-667.

Kaenmaki M, Tammimaki A, Myohanen T, Pakarinen K, Amberg C, Karayiorgou $\mathrm{M}$ et al (2010). Quantitative role of COMT in dopamine clearance in the prefrontal cortex of freely moving mice. J Neurochem 114: 1745-1755.

Kalivas PW, Churchill L, Klitenick MA (1993). GABA and enkephalin projection from the nucleus accumbens and ventral pallidum to the ventral tegmental area. Neuroscience 57: 1047-1060.

Kalivas PW, Duffy P (1998). Repeated cocaine administration alters extracellular glutamate in the ventral tegmental area. J Neurochem 70: 1497-1502.

Kalivas PW, McFarland K (2003). Brain circuitry and the reinstatement of cocaine-seeking behavior. Psychopharmacology (Berl) 168: 44-56.

Kim JI, Ganesan S, Luo SX, Wu YW, Park E, Huang EJ et al (2015). Aldehyde dehydrogenase lal mediates a GABA synthesis pathway in midbrain dopaminergic neurons. Science 350: 102-106.

Kitai ST, Shepard PD, Callaway JC, Scroggs R (1999). Afferent modulation of dopamine neuron firing patterns. Curr Opin Neurobiol 9: 690-697.

Klink R, de Kerchove d'Exaerde A, Zoli M, Changeux JP (2001). Molecular and physiological diversity of nicotinic acetylcholine receptors in the midbrain dopaminergic nuclei. J Neurosci 21: $1452-1463$.
Koo JW, Mazei-Robison MS, Chaudhury D, Juarez B, LaPlant Q, Ferguson D et al (2012). BDNF is a negative modulator of morphine action. Science 338: 124-128.

Koob GF (2006). The neurobiology of addiction: a neuroadaptational view relevant for diagnosis. Addiction 101(Suppl 1): 23-30.

Koob GF (2008). A role for brain stress systems in addiction. Neuron 59: 11-34.

Koob GF, Buck CL, Cohen A, Edwards S, Park PE, Schlosburg JE et al (2014). Addiction as a stress surfeit disorder. Neuropharmacology 76(Pt B): 370-382.

Koob GF, Volkow ND (2010). Neurocircuitry of addiction. Neuropsychopharmacology 35: 217-238.

Korotkova TM, Brown RE, Sergeeva OA, Ponomarenko AA, Haas HL (2006). Effects of arousal- and feeding-related neuropeptides on dopaminergic and GABAergic neurons in the ventral tegmental area of the rat. Eur J Neurosci 23: 2677-2685.

Korotkova TM, Sergeeva OA, Eriksson KS, Haas HL, Brown RE (2003). Excitation of ventral tegmental area dopaminergic and nondopaminergic neurons by orexins/hypocretins. J Neurosci 23: $7-11$.

Koulchitsky S, De Backer B, Quertemont E, Charlier C, Seutin V (2012). Differential effects of cocaine on dopamine neuron firing in awake and anesthetized rats. Neuropsychopharmacology 37: 1559-1571.

Kozell LB, Meshul CK (2001). The effects of acute or repeated cocaine administration on nerve terminal glutamate within the rat mesolimbic system. Neuroscience 106: 15-25.

Labouebe G, Lomazzi M, Cruz HG, Creton C, Lujan R, Li M et al (2007). RGS2 modulates coupling between GABAB receptors and GIRK channels in dopamine neurons of the ventral tegmental area. Nat Neurosci 10: 1559-1568.

Lammel S, Hetzel A, Hackel O, Jones I, Liss B, Roeper J (2008). Unique properties of mesoprefrontal neurons within a dual mesocorticolimbic dopamine system. Neuron 57: 760-773.

Lammel S, Ion DI, Roeper J, Malenka RC (2011). Projection-specific modulation of dopamine neuron synapses by aversive and rewarding stimuli. Neuron 70: 855-862.

Lammel S, Lim BK, Malenka RC (2014). Reward and aversion in a heterogeneous midbrain dopamine system. Neuropharmacology 76(Pt B): 351-359.

Lammel S, Lim BK, Ran C, Huang KW, Betley MJ, Tye KM et al (2012). Input-specific control of reward and aversion in the ventral tegmental area. Nature 491: 212-217.

Laviolette SR, van der Kooy D (2004). The neurobiology of nicotine addiction: bridging the gap from molecules to behaviour. Nat Rev Neurosci 5: 55-65.

Lawrence AJ, Cowen MS, Yang HJ, Chen F, Oldfield B (2006). The orexin system regulates alcohol-seeking in rats. $\mathrm{Br} J$ Pharmacol 148: $752-759$.

Lecca S, Melis M, Luchicchi A, Muntoni AL, Pistis M (2011). Inhibitory inputs from rostromedial tegmental neurons regulate spontaneous activity of midbrain dopamine cells and their responses to drugs of abuse. Neuropsychopharmacology 37: 1164-1176.

Leone P, Pocock D, Wise RA (1991). Morphine-dopamine interaction: ventral tegmental morphine increases nucleus accumbens dopamine release. Pharmacol Biochem Behav 39: 469-472.

Lewis DA, Melchitzky DS, Sesack SR, Whitehead RE, Auh S, Sampson A (2001). Dopamine transporter immunoreactivity in monkey cerebral cortex: regional, laminar, and ultrastructural localization. J Comp Neurol 432: 119-136.

Li W, Doyon WM, Dani JA (2011). Acute in vivo nicotine administration enhances synchrony among dopamine neurons. Biochem Pharmacol 82: 977-983.

Lisman JE, Grace AA (2005). The hippocampal-VTA loop: controlling the entry of information into long-term memory. Neuron 46: 703-713. 
Liss B, Roeper J (2008). Individual dopamine midbrain neurons: functional diversity and flexibility in health and disease. Brain Res Rev 58: 314-321.

Liu QS, Pu L, Poo MM (2005). Repeated cocaine exposure in vivo facilitates LTP induction in midbrain dopamine neurons. Nature 437: 1027-1031.

Lodge DJ, Grace AA (2005). Acute and chronic corticotropinreleasing factor 1 receptor blockade inhibits cocaine-induced dopamine release: correlation with dopamine neuron activity. J Pharmacol Exp Ther 314: 201-206.

Lodge DJ, Grace AA (2006). The laterodorsal tegmentum is essential for burst firing of ventral tegmental area dopamine neurons. Proc Natl Acad Sci USA 103: 5167-5172.

Lovinger DM, White G, Weight FF (1989). Ethanol inhibits NMDAactivated ion current in hippocampal neurons. Science 243: $1721-1724$.

Luscher C (2013). Cocaine-evoked synaptic plasticity of excitatory transmission in the ventral tegmental area. Cold Spring Harb Perspect Med 3: a012013.

Mameli-Engvall M, Evrard A, Pons S, Maskos U, Svensson TH, Changeux JP et al (2006). Hierarchical control of dopamine neuron-firing patterns by nicotinic receptors. Neuron 50: 911-921.

Mameli M, Bellone C, Brown MT, Luscher C (2011). Cocaine inverts rules for synaptic plasticity of glutamate transmission in the ventral tegmental area. Nat Neurosci 14: 414-416.

Mansvelder HD, Keath JR, McGehee DS (2002a). Synaptic mechanisms underlie nicotine-induced excitability of brain reward areas. Neuron 33: 905-919.

Mansvelder HD, McGehee DS (2002b). Cellular and synaptic mechanisms of nicotine addiction. J Neurobiol 53: 606-617.

Margolis EB, Coker AR, Driscoll JR, Lemaitre AI, Fields HL (2010). Reliability in the identification of midbrain dopamine neurons. PLoS One 5: e15222.

Margolis EB, Hjelmstad GO, Fujita W, Fields HL (2014). Direct bidirectional mu-opioid control of midbrain dopamine neurons. J Neurosci 34: 14707-14716.

Margolis EB, Lock H, Chefer VI, Shippenberg TS, Hjelmstad GO, Fields HL (2006a). Kappa opioids selectively control dopaminergic neurons projecting to the prefrontal cortex. Proc Natl Acad Sci USA 103: 2938-2942.

Margolis EB, Lock H, Hjelmstad GO, Fields HL (2006b). The ventral tegmental area revisited: is there an electrophysiological marker for dopaminergic neurons? J Physiol 577: 907-924.

Margolis EB, Mitchell JM, Ishikawa J, Hjelmstad GO, Fields HL (2008). Midbrain dopamine neurons: projection target determines action potential duration and dopamine $\mathrm{D}(2)$ receptor inhibition. J Neurosci 28: 8908-8913.

Marinelli M, Aouizerate B, Barrot M, Le Moal M, Piazza PV (1998). Dopamine-dependent responses to morphine depend on glucocorticoid receptors. Proc Natl Acad Sci USA 95: 7742-7747.

Marinelli M, Piazza PV (2002). Interaction between glucocorticoid hormones, stress and psychostimulant drugs. Eur J Neurosci 16: 387-394.

Marti F, Arib O, Morel C, Dufresne V, Maskos U, Corringer PJ et al (2011). Smoke extracts and nicotine, but not tobacco extracts, potentiate firing and burst activity of ventral tegmental area dopaminergic neurons in mice. Neuropsychopharmacology 36: 2244-2257.

Maskos U, Molles BE, Pons S, Besson M, Guiard BP, Guilloux JP et al (2005). Nicotine reinforcement and cognition restored by targeted expression of nicotinic receptors. Nature 436: 103-107.

Matsui A, Jarvie BC, Robinson BG, Hentges ST, Williams JT (2014). Separate GABA afferents to dopamine neurons mediate acute action of opioids, development of tolerance, and expression of withdrawal. Neuron 82: 1346-1356.

Matsui A, Williams JT (2011). Opioid-sensitive GABA inputs from rostromedial tegmental nucleus synapse onto midbrain dopamine neurons. J Neurosci 31: 17729-17735.
Matsumoto M, Hikosaka O (2007). Lateral habenula as a source of negative reward signals in dopamine neurons. Nature 447: $1111-1115$.

Mazei-Robison MS, Nestler EJ (2012). Opiate-induced molecular and cellular plasticity of ventral tegmental area and locus coeruleus catecholamine neurons. Cold Spring Harb Perspect Med 2: a012070.

McEwen BS, Bowles NP, Gray JD, Hill MN, Hunter RG, Karatsoreos IN et al (2015). Mechanisms of stress in the brain. Nat Neurosci 18: 1353-1363.

McFarland K, Davidge SB, Lapish CC, Kalivas PW (2004). Limbic and motor circuitry underlying footshock-induced reinstatement of cocaine-seeking behavior. J Neurosci 24: 1551-1560.

McGehee DS, Role LW (1995). Physiological diversity of nicotinic acetylcholine receptors expressed by vertebrate neurons. Annu Rev Physiol 57: 521-546.

McLaughlin JP, Marton-Popovici M, Chavkin C (2003). Kappa opioid receptor antagonism and prodynorphin gene disruption block stress-induced behavioral responses. J Neurosci 23: 5674-5683.

Mejias-Aponte CA, Drouin C, Aston-Jones G (2009). Adrenergic and noradrenergic innervation of the midbrain ventral tegmental area and retrorubral field: prominent inputs from medullary homeostatic centers. J Neurosci 29: 3613-3626.

Mejias-Aponte CA, Ye C, Bonci A, Kiyatkin EA, Morales M (2015). A subpopulation of neurochemically-identified ventral tegmental area dopamine neurons is excited by intravenous cocaine. J Neurosci 35: 1965-1978.

Melis M, Camarini R, Ungless MA, Bonci A (2002). Long-lasting potentiation of GABAergic synapses in dopamine neurons after a single in vivo ethanol exposure. J Neurosci 22: 2074-2082.

Moghaddam B, Berridge CW, Goldman-Rakic PS, Bunney BS, Roth RH (1993). In vivo assessment of basal and drug-induced dopamine release in cortical and subcortical regions of the anesthetized primate. Synapse 13: 215-222.

Morel C, Fattore L, Pons S, Hay YA, Marti F, Lambolez B et al (2013). Nicotine consumption is regulated by a human polymorphism in dopamine neurons. Mol Psychiatry 19: 930-936.

Morikawa H, Morrisett RA (2010). Ethanol action on dopaminergic neurons in the ventral tegmental area: interaction with intrinsic ion channels and neurotransmitter inputs. Int Rev Neurobiol 91: 235-288.

Mrejeru A, Marti-Prats L, Avegno EM, Harrison NL, Sulzer D (2015). A subset of ventral tegmental area dopamine neurons responds to acute ethanol. Neuroscience 290: 649-658.

Narita M, Nagumo Y, Hashimoto S, Khotib J, Miyatake M, Sakurai T et al (2006). Direct involvement of orexinergic systems in the activation of the mesolimbic dopamine pathway and related behaviors induced by morphine. J Neurosci 26: 398-405.

Nestler EJ (2001). Molecular basis of long-term plasticity underlying addiction. Nat Rev Neurosci 2: 119-128.

Nestler EJ (2005). Is there a common molecular pathway for addiction? Nat Neurosci 8: 1445-1449.

Nimitvilai S, Herman M, You C, Arora DS, McElvain MA, Roberto M et al (2014). Dopamine D2 receptor desensitization by dopamine or corticotropin releasing factor in ventral tegmental area neurons is associated with increased glutamate release. Neuropharmacology 82: 28-40.

Nisell M, Nomikos GG, Svensson TH (1994). Infusion of nicotine in the ventral tegmental area or the nucleus accumbens of the rat differentially affects accumbal dopamine release. Pharmacol Toxicol 75: 348-352.

Nugent FS, Penick EC, Kauer JA (2007). Opioids block long-term potentiation of inhibitory synapses. Nature 446: 1086-1090.

Oakman SA, Faris PL, Kerr PE, Cozzari C, Hartman BK (1995). Distribution of pontomesencephalic cholinergic neurons projecting to substantia nigra differs significantly from those projecting to ventral tegmental area. J Neurosci 15: 5859-5869. 
Okamoto T, Harnett MT, Morikawa H (2006). Hyperpolarizationactivated cation current (Ih) is an ethanol target in midbrain dopamine neurons of mice. J Neurophysiol 95: 619-626.

Olmstead MC, Franklin KB (1997). The development of a conditioned place preference to morphine: effects of lesions of various CNS sites. Behav Neurosci 111: 1313-1323.

Omelchenko N, Sesack SR (2005). Laterodorsal tegmental projections to identified cell populations in the rat ventral tegmental area. J Comp Neurol 483: 217-235.

Overton PG, Tong ZY, Brain PF, Clark D (1996). Preferential occupation of mineralocorticoid receptors by corticosterone enhances glutamate-induced burst firing in rat midbrain dopaminergic neurons. Brain Res 737: 146-154.

Pacak K (2000). Stressor-specific activation of the hypothalamicpituitary-adrenocortical axis. Physiol Res 49(Suppl 1): S11-S17.

Perra S, Clements MA, Bernier BE, Morikawa H (2011). In vivo ethanol experience increases $\mathrm{D}(2)$ autoinhibition in the ventral tegmental area. Neuropsychopharmacology 36: 993-1002.

Peyron C, Tighe DK, van den Pol AN, de Lecea L, Heller HC, Sutcliffe JG et al (1998). Neurons containing hypocretin (orexin) project to multiple neuronal systems. J Neurosci 18: 9996-10015.

Phillips PE, Stuber GD, Heien ML, Wightman RM, Carelli RM (2003). Subsecond dopamine release promotes cocaine seeking. Nature 422: 614-618.

Piazza PV, Le Moal ML (1996). Pathophysiological basis of vulnerability to drug abuse: role of an interaction between stress, glucocorticoids, and dopaminergic neurons. Annu Rev Pharmacol Toxicol 36: 359-378.

Picciotto MR, Zoli M, Rimondini R, Lena C, Marubio LM, Pich EM et al (1998). Acetylcholine receptors containing the beta2 subunit are involved in the reinforcing properties of nicotine. Nature 391: 173-177.

Pidoplichko VI, DeBiasi M, Williams JT, Dani JA (1997). Nicotine activates and desensitizes midbrain dopamine neurons. Nature 390: 401-404.

Pignatelli M, Bonci A (2015). Role of dopamine neurons in reward and aversion: a synaptic plasticity perspective. Neuron 86: 1145-1157.

Pons S, Fattore L, Cossu G, Tolu S, Porcu E, McIntosh JM et al (2008). Crucial role of alpha4 and alpha6 nicotinic acetylcholine receptor subunits from ventral tegmental area in systemic nicotine self-administration. J Neurosci 28: 12318-12327.

$\mathrm{Pu}$ L, Liu QS, Poo MM (2006). BDNF-dependent synaptic sensitization in midbrain dopamine neurons after cocaine withdrawal. Nat Neurosci 9: 605-607.

Reperant C, Pons S, Dufour E, Rollema H, Gardier AM, Maskos U (2010). Effect of the alpha4beta $2^{\star}$ nicotinic acetylcholine receptor partial agonist varenicline on dopamine release in beta2 knockout mice with selective re-expression of the beta 2 subunit in the ventral tegmental area. Neuropharmacology 58: 346-350.

Rivera-Meza M, Quintanilla ME, Bustamante D, Delgado R, Buscaglia M, Herrera-Marschitz M (2014). Overexpression of hyperpolarization-activated cyclic nucleotide-gated channels into the ventral tegmental area increases the rewarding effects of ethanol in UChB drinking rats. Alcohol Clin Exp Res 38: 911-920.

Robinson TE, Berridge KC (2000). The psychology and neurobiology of addiction: an incentive-sensitization view. Addiction 95 (Suppl 2): S91-117.

Rodaros D, Caruana DA, Amir S, Stewart J (2007). Corticotropinreleasing factor projections from limbic forebrain and paraventricular nucleus of the hypothalamus to the region of the ventral tegmental area. Neuroscience 150: 8-13.

Rodd-Henricks ZA, McKinzie DL, Crile RS, Murphy JM, McBride WJ (2000). Regional heterogeneity for the intracranial selfadministration of ethanol within the ventral tegmental area of female Wistar rats. Psychopharmacology (Berl) 149: 217-224.

Roesch MR, Calu DJ, Schoenbaum G (2007). Dopamine neurons encode the better option in rats deciding between differently delayed or sized rewards. Nat Neurosci 10: 1615-1624.
Rouge-Pont F, Marinelli M, Le Moal M, Simon H, Piazza PV (1995). Stress-induced sensitization and glucocorticoids. II. Sensitization of the increase in extracellular dopamine induced by cocaine depends on stress-induced corticosterone secretion. J Neurosci 15: 7189-7195.

Russo SJ, Nestler EJ (2013). The brain reward circuitry in mood disorders. Nat Rev Neurosci 14: 609-625.

Saal D, Dong Y, Bonci A, Malenka RC (2003). Drugs of abuse and stress trigger a common synaptic adaptation in dopamine neurons. Neuron 37: 577-582.

Sakurai T, Amemiya A, Ishii M, Matsuzaki I, Chemelli RM, Tanaka H et al (1998). Orexins and orexin receptors: a family of hypothalamic neuropeptides and $G$ protein-coupled receptors that regulate feeding behavior. Cell 92: 573-585.

Sanchez-Catalan MJ, Kaufling J, Georges F, Veinante P, Barrot M (2014). The antero-posterior heterogeneity of the ventral tegmental area. Neuroscience 282C: 198-216.

Sanchis-Segura C, Spanagel R (2006). Behavioural assessment of drug reinforcement and addictive features in rodents: an overview. Addict Biol 11: 2-38.

Sauvage M, Steckler T (2001). Detection of corticotropin-releasing hormone receptor 1 immunoreactivity in cholinergic, dopaminergic and noradrenergic neurons of the murine basal forebrain and brainstem nuclei-potential implication for arousal and attention. Neuroscience 104: 643-652.

Scatton B, Simon H, Le Moal M, Bischoff S (1980). Origin of dopaminergic innervations of the rat hippocampal formation. Neurosci Lett 18: 125-131.

Schenk S, Ellison F, Hunt T, Amit Z (1985). An examination of heroin conditioning in preferred and nonpreferred environments and in differentially housed mature and immature rats. Pharmacol Biochem Behav 22: 215-220.

Schultz W (2002). Getting formal with dopamine and reward. Neuron 36: 241-263.

Schultz W (2007). Behavioral dopamine signals. Trends Neurosci 30: 203-210.

Schultz W, Dayan P, Montague PR (1997). A neural substrate of prediction and reward. Science 275: 1593-1599.

Seguela P, Wadiche J, Dineley-Miller K, Dani JA, Patrick JW (1993). Molecular cloning, functional properties, and distribution of rat brain alpha 7: a nicotinic cation channel highly permeable to calcium. J Neurosci 13: 596-604.

Sesack SR, Bunney BS (1989). Pharmacological characterization of the receptor mediating electrophysiological responses to dopamine in the rat medial prefrontal cortex: a microiontophoretic study. J Pharmacol Exp Ther 248: 1323-1333.

Sesack SR, Carr DB (2002). Selective prefrontal cortex inputs to dopamine cells: implications for schizophrenia. Physiol Behav 77: 513-517.

Sesack SR, Hawrylak VA, Matus C, Guido MA, Levey AI (1998). Dopamine axon varicosities in the prelimbic division of the rat prefrontal cortex exhibit sparse immunoreactivity for the dopamine transporter. J Neurosci 18: 2697-2708.

Shaham Y (1993). Immobilization stress-induced oral opioid selfadministration and withdrawal in rats: role of conditioning factors and the effect of stress on 'relapse' to opioid drugs. Psychopharmacology (Berl) 111: 477-485.

Shaham Y, Stewart J (1994). Exposure to mild stress enhances the reinforcing efficacy of intravenous heroin self-administration in rats. Psychopharmacology (Berl) 114: 523-527.

Siciliano CA, Calipari ES, Ferris MJ, Jones SR (2015). Adaptations of presynaptic dopamine terminals induced by psychostimulant self-administration. ACS Chem Neurosci 6: 27-36.

Smith RJ, Tahsili-Fahadan P, Aston-Jones G (2009). Orexin/ hypocretin is necessary for context-driven cocaine-seeking. Neuropharmacology 58: 179-184.

Sparta DR, Hopf FW, Gibb SL, Cho SL, Stuber GD, Messing RO et al (2013). Binge ethanol-drinking potentiates corticotropin 
releasing factor R1 receptor activity in the ventral tegmental area. Alcohol Clin Exp Res 37: 1680-1687.

Steffensen SC, Stobbs SH, Colago EE, Lee RS, Koob GF, Gallegos RA et al (2006). Contingent and non-contingent effects of heroin on mu-opioid receptor-containing ventral tegmental area GABA neurons. Exp Neurol 202: 139-151.

Stobbs SH, Ohran AJ, Lassen MB, Allison DW, Brown JE, Steffensen SC (2004). Ethanol suppression of ventral tegmental area GABA neuron electrical transmission involves N-methyl-Daspartate receptors. J Pharmacol Exp Ther 311: 282-289.

Stuber GD, Hnasko TS, Britt JP, Edwards RH, Bonci A (2010). Dopaminergic terminals in the nucleus accumbens but not the dorsal striatum corelease glutamate. J Neurosci 30: 8229-8233.

Sulzer D (2011). How addictive drugs disrupt presynaptic dopamine neurotransmission. Neuron 69: 628-649.

Swanson LW, Sawchenko PE, Rivier J, Vale WW (1983). Organization of ovine corticotropin-releasing factor immunoreactive cells and fibers in the rat brain: an immunohistochemical study. Neuroendocrinology 36: 165-186.

Tagliaferro P, Morales M (2008). Synapses between corticotropinreleasing factor- containing axon terminals and dopaminergic neurons in the ventral tegmental area are predominantly glutamatergic. J Comp Neurol 506: 616-626.

Takahashi YK, Roesch MR, Wilson RC, Toreson K, O'Donnell P, Niv Y et al (2011). Expectancy-related changes in firing of dopamine neurons depend on orbitofrontal cortex. Nat Neurosci 14: 1590-1597.

Tan KR, Brown M, Labouebe G, Yvon C, Creton C, Fritschy JM et al (2010). Neural bases for addictive properties of benzodiazepines. Nature 463: 769-774.

Theile JW, Morikawa H, Gonzales RA, Morrisett RA (2008). Ethanol enhances GABAergic transmission onto dopamine neurons in the ventral tegmental area of the rat. Alcohol Clin Exp Res 32: 1040-1048.

Theile JW, Morikawa H, Gonzales RA, Morrisett RA (2010). GABAergic transmission modulates ethanol excitation of ventral tegmental area dopamine neurons. Neuroscience 172: 94-103.

Tolu S, Eddine R, Marti F, David V, Graupner M, Pons S et al (2012). Co-activation of VTA DA and GABA neurons mediates nicotine reinforcement. Mol Psychiatry 18: 382-393.

Tolu S, Eddine R, Marti F, David V, Graupner M, Pons S et al (2013). Co-activation of VTA DA and GABA neurons mediates nicotine reinforcement. Mol Psychiatry 18: 382-393.

Tong ZY, Overton PG, Clark D (1996a). Antagonism of NMDA receptors but not AMPA/kainate receptors blocks bursting in dopaminergic neurons induced by electrical stimulation of the prefrontal cortex. J Neural Transm (Vienna) 103: 889-904.

Tong ZY, Overton PG, Clark D (1996b). Stimulation of the prefrontal cortex in the rat induces patterns of activity in midbrain dopaminergic neurons which resemble natural burst events. Synapse 22: 195-208.

Tritsch NX, Ding JB, Sabatini BL (2012). Dopaminergic neurons inhibit striatal output through non-canonical release of GABA. Nature 490: 262-266.

Tritsch NX, Oh WJ, Gu C, Sabatini BL (2014). Midbrain dopamine neurons sustain inhibitory transmission using plasma membrane uptake of GABA, not synthesis. Elife 3: e01936.

Tsai HC, Zhang F, Adamantidis A, Stuber GD, Bonci A, de Lecea L et al (2009). Phasic firing in dopaminergic neurons is sufficient for behavioral conditioning. Science 324: 1080-1084.

Tye KM, Mirzabekov JJ, Warden MR, Ferenczi EA, Tsai HC, Finkelstein J et al (2013). Dopamine neurons modulate neural encoding and expression of depression-related behaviour. Nature 493: $537-541$.

Ungless MA, Grace AA (2012). Are you or aren't you? Challenges associated with physiologically identifying dopamine neurons. Trends Neurosci 35: 422-430.

Ungless MA, Magill PJ, Bolam JP (2004). Uniform inhibition of dopamine neurons in the ventral tegmental area by aversive stimuli. Science 303: 2040-2042.
Ungless MA, Singh V, Crowder TL, Yaka R, Ron D, Bonci A (2003). Corticotropin-releasing factor requires CRF binding protein to potentiate NMDA receptors via CRF receptor 2 in dopamine neurons. Neuron 39: 401-407.

Ungless MA, Whistler JL, Malenka RC, Bonci A (2001). Single cocaine exposure in vivo induces long-term potentiation in dopamine neurons. Nature 411: 583-587.

Valenti O, Lodge DJ, Grace AA (2011). Aversive stimuli alter ventral tegmental area dopamine neuron activity via a common action in the ventral hippocampus. J Neurosci 31: 4280-4289.

Van Pett K, Viau V, Bittencourt JC, Chan RK, Li HY, Arias C et al (2000). Distribution of mRNAs encoding CRF receptors in brain and pituitary of rat and mouse. J Comp Neurol 428: 191-212.

Vanderschuren LJ, Kalivas PW (2000). Alterations in dopaminergic and glutamatergic transmission in the induction and expression of behavioral sensitization: a critical review of preclinical studies. Psychopharmacology (Berl) 151: 99-120.

Vaughan RA, Foster JD (2013). Mechanisms of dopamine transporter regulation in normal and disease states. Trends Pharmacol Sci 34: 489-496.

Vittoz NM, Berridge CW (2006). Hypocretin/orexin selectively increases dopamine efflux within the prefrontal cortex: involvement of the ventral tegmental area. Neuropsychopharmacology 31: 384-395.

Vittoz NM, Schmeichel B, Berridge CW (2008). Hypocretin /orexin preferentially activates caudomedial ventral tegmental area dopamine neurons. Eur J Neurosci 28: 1629-1640.

Wada K, Ballivet M, Boulter J, Connolly J, Wada E, Deneris ES et al (1988). Functional expression of a new pharmacological subtype of brain nicotinic acetylcholine receptor. Science 240: 330-334.

Wallace DM, Magnuson DJ, Gray TS (1992). Organization of amygdaloid projections to brainstem dopaminergic, noradrenergic, and adrenergic cell groups in the rat. Brain Res Bull 28: 447-454.

Walsh JJ, Han MH (2014). The heterogeneity of ventral tegmental area neurons: projection functions in a mood-related context. Neuroscience 282C: 101-108.

Wanat MJ, Sparta DR, Hopf FW, Bowers MS, Melis M, Bonci A (2009). Strain specific synaptic modifications on ventral tegmental area dopamine neurons after ethanol exposure. Biol Psychiatry 65: 646-653.

Wang B, Shaham Y, Zitzman D, Azari S, Wise RA, You ZB (2005). Cocaine experience establishes control of midbrain glutamate and dopamine by corticotropin-releasing factor: a role in stressinduced relapse to drug seeking. J Neurosci 25: 5389-5396.

Wang B, You ZB, Rice KC, Wise RA (2007). Stress-induced relapse to cocaine seeking: roles for the $\operatorname{CRF}(2)$ receptor and CRF-binding protein in the ventral tegmental area of the rat. Psychopharmacology (Berl) 193: 283-294.

Wang JC, Cruchaga C, Saccone NL, Bertelsen S, Liu P, Budde JP et al (2009). Risk for nicotine dependence and lung cancer is conferred by mRNA expression levels and amino acid change in CHRNA5. Hum Mol Genet 18: 3125-3135.

Weiss F, Lorang MT, Bloom FE, Koob GF (1993). Oral alcohol selfadministration stimulates dopamine release in the rat nucleus accumbens: genetic and motivational determinants. J Pharmacol Exp Ther 267: 250-258.

Weiss F, Parsons LH, Schulteis G, Hyytia P, Lorang MT, Bloom FE et al (1996). Ethanol self-administration restores withdrawal-associated deficiencies in accumbal dopamine and 5-hydroxytryptamine release in dependent rats. J Neurosci 16: 3474-3485.

Weiss F, Porrino LJ (2002). Behavioral neurobiology of alcohol addiction: recent advances and challenges. J Neurosci 22: 3332-3337.

Wise RA, Morales M (2009). A ventral tegmental CRF-glutamatedopamine interaction in addiction. Brain Res 1314: 38-43.

Wise RA, Rompre PP (1989). Brain dopamine and reward. Annu Rev Psychol 40: 191-225. 
Wonnacott S, Sidhpura N, Balfour DJ (2005). Nicotine: from molecular mechanisms to behaviour. Curr Opin Pharmacol 5: 53-59.

Wu M, Hrycyshyn AW, Brudzynski SM (1996). Subpallidal outputs to the nucleus accumbens and the ventral tegmental area: anatomical and electrophysiological studies. Brain Res 740: 151-161.

Zahm DS, Heimer L (1990). Two transpallidal pathways originating in the rat nucleus accumbens. J Comp Neurol 302: 437-446.

Zhu Y, Miwa Y, Yamanaka A, Yada T, Shibahara M, Abe Y et al (2003). Orexin receptor type-1 couples exclusively to pertussis toxin-insensitive G-proteins, while orexin receptor type-2 couples to both pertussis toxin-sensitive and -insensitive G-proteins. J Pharmacol Sci 92: 259-266.

Zweifel LS, Fadok JP, Argilli E, Garelick MG, Jones GL, Dickerson TM et al (2011). Activation of dopamine neurons is critical for aversive conditioning and prevention of generalized anxiety. Nat Neurosci 14: 620-626.
Zweifel LS, Parker JG, Lobb CJ, Rainwater A, Wall VZ, Fadok JP et al (2009). Disruption of NMDAR-dependent burst firing by dopamine neurons provides selective assessment of phasic dopamine-dependent behavior. Proc Natl Acad Sci USA 106: 7281-7288.

(c) (i) This work is licensed under a Creative Commons Attribution 4.0 International License. The images or other third party material in this article are included in the article's Creative Commons license, unless indicated otherwise in the credit line; if the material is not included under the Creative Commons license, users will need to obtain permission from the license holder to reproduce the material. To view a copy of this license, visit http://creativecommons.org/licenses/ by/4.0/ 